\title{
Mergers and Acquisitions Strategy under Imperfect Information: A Mixed-payment Model*
}

\author{
Wenjun Chen ${ }^{\dagger}$ \\ Graduate School of Economics and Business, Hokkaido University
}

\begin{abstract}
This paper develops a dynamic model of a joint takeover to determine the timing, acquisition premiums, and terms. The model incorporates imperfect information and the strategy by solving a Markov perfect Nash equilibrium. The results predict that the acquirer will make a high cash payment to the target to gain high post-merger management control. The abnormal return to the participating firm can be positive or negative due to asymmetric information. In addition, the model relates the acquisition premium payment and the merger threshold to the growth rate, volatility, and correlation coefficient of the acquirer and target.
\end{abstract}

Keywords: M\&A terms; Real options; Takeover; Acquisition premium; Synergy; Bargaining power

\footnotetext{
${ }^{*}$ Received: July 18, 2017; Accepted: October 18, 2017.

${ }^{\dagger}$ Corresponding author. Address: Kita 9, Nishi 7, Kita-ku, Sapporo 060-0809, Japan; Phone: +81-11-706-3183; E-mail: chenwenjun@eis.hokudai.ac.jp
} 


\section{Introduction}

Generally, enterprises can grow in two ways: the first is by expanding production, which is internal reinvestment; the second is by acquisition and reorganization. Acquisitions will create synergies from cost savings, customer expansion, or other financial benefits resulting from the cooperation of two firms.

The optimal timing and post-merger ownership structure are two keys in the analysis of merger and acquisition strategies. Several well-known studies have analyzed the timing and terms of mergers and acquisitions. Lambrecht [10] studies the timing and terms of mergers motivated by economies of scale and shows that merger activities are positively correlated with markets, meaning that firms are willing to merge during economic expansions. Thijssen [21] builds on Lambrecht [10] to build a two-uncertainty model that optimizes the timing considering both efficiency gains and diversification benefits. The results show that mergers and acquisitions will happen during both economic upswings and downswings. Bernile, Lyandres and Zhdanov [2], Hackbarth and Morellec [8], and Lambrecht and Myers [11] also develop models featuring optimal timing. Hackbarth and Miao [7] develop a joint model of oligopolistic industries that determines the industry's product equilibrium, as well as the timing and terms of takeovers. The result shows the relationship between the return from merging and firm size. In terms of firm-size analysis, Moeller, Schlingemann, and Stulz [15] show the firm-size effect in acquisition announcement returns.

Gaughan [5] explained that mergers may be paid for in several ways. In this paper, transactions involving all cash, all securities, or a combination of cash and securities are termed pure cash mergers, pure share (stock-for-stock) mergers, and mixed-payment mergers, respectively. The studies described above assume pure share (stock-for-stock) merger conditions in their models, with no cash-payment made. In stock-for-stock mergers, both participating firms remain shareholders in the continuing combined enterprise. They negotiate the post-merger structure based on the pre-transaction ratio of the firms' market value.

In the pure cash mergers, the acquirer pays an equivalent cash amount to the target and buys the whole target company. As a result, the acquirer holds all the shares of the merged firm. Lukas and Welling [12] and Lukas, Reuer and Welling [13] develop two-stage models analyzing the price and timing of merger and acquisition. Offenberg and Pirinsky [18] prove the acquirers who prefer a faster execution would tend to structure the acquisition as a tender offer. Tender offers also come with a higher cost. The acquirers hope for a trade-off between the execution speed benefits of tender offers and the lower premium benefits of mergers.

In the mixed-payment type, the acquirer pays both cash and shares to the target, and shareholders of both firms maintain ownership in the new firm. Compared with pure cash and pure share mergers, mixed-payment mergers are increasing in importance. Goergen and Renneboog [6] analyze 156 takeover bid samples in Europe during the 1990s; of the sample, 93 and 37 were pure cash and pure share, respectively, with 18 cases of the mixed-payment type. pure share offers trigger much larger share price reactions than other two types. A study by Faccio and Masulis [4] shows that $11.3 \%$ of a sample of European 3,667 mergers or acquisitions are mixed-payment mergers, and these deals always have a larger transaction size. In Martynova and Renneboog [14], the proposition of the mixed-payment mergers increased to $19 \%$ in a sample of 1,361 European acquisitions. de La Bruslerie 
[9] examines the combination of cash and share payments in the context of an acquisition process. For the acquirer, the cash-payment portion increases with expectation of acquisition gains and synergy.

This study develops a model of mixed-payment mergers in which both the acquirer and target remain shareholders of the new combined enterprise and negotiate over the post-merger terms. The acquirer pays a cash premium to the target. Acquirers may have many motivations to pay a cash premium. In this paper, we assume that the acquirer pays a cash premium to negotiate better post-merger terms in the new firm. This study aims to establish a joint merger model of timing, cash acquisition premium, and terms in markets with both perfect and imperfect information. Furthermore, the model will examine the effect of information on the decision making.

In this study, we base our analysis on Morellec and Zhdanov [16]'s model of a joint determination of timing and terms of takeovers under competition and imperfect information. The model set-up is closely related to Hackbarth and Morellec [8] and Shleifer and Vishny [19], who develop a model based on the stock market misvaluation of the merged firms and compares the stock returns of the participating firms in both the long- and short-run.

We extend the model to study the returns generated under asymmetric information. This study also differs from previous studies in several important dimensions. The three main contributions of this study are as follows. First, we consider a cash premium, which Morellec and Zhdanov [16] do not include. We establish the model using a non-cooperative game in which the acquirer provides a tender offer, and the target can either accept the offer or wait. The study is also closely related to Lukas and Welling [12], who develop a two-stage model analyzing the pricing and timing of mergers and acquisitions.

Second, we analyze the terms, assuming that the acquirer and target will negotiate the terms of the merged enterprise, which we solve via a Nash barging solution [17]. Several studies combine game theory and real options theory. Azevedo and Paxson [1] discuss the discrete- and continuous-time frameworks of a standard real options game and review two decades of academic research on standard and non-standard real options games. Lukas, Reuer and Welling [13] use a game-theoretic option approach to model the value of contingent earnouts, finding that the firm will tend to postpone the investment under larger transaction costs, greater uncertainty in cash flows, a longer earnout period, and higher performance targets.

Finally, we assume that both the acquirer and target will probably misestimate the price, and that the managers of both firms can take advantage of this. In Morellec and Zhdanov [16], asymmetric information occurs between the participating firms and investors. The paper analyzes the abnormal returns from the announcement. We extend the model by assuming asymmetric information between the two participating firms.

This study examines two scenarios. The first is the single acquirer case in which we develop a basic model of the target acquisition in a market with perfect information, without competition. We then extend the model to a second scenario with asymmetric information. The price of both the acquirer and target may be misestimated, which means the market price may be higher or lower than the real price. However, both participating firms have complete information about their own firm. Therefore, they will generate an optimal strategy using the estimated parameters based on the available information. The merger and acquisition activities can increase information disclosure and push the market price towards the real value. Therefore, the model generates abnormal returns to 


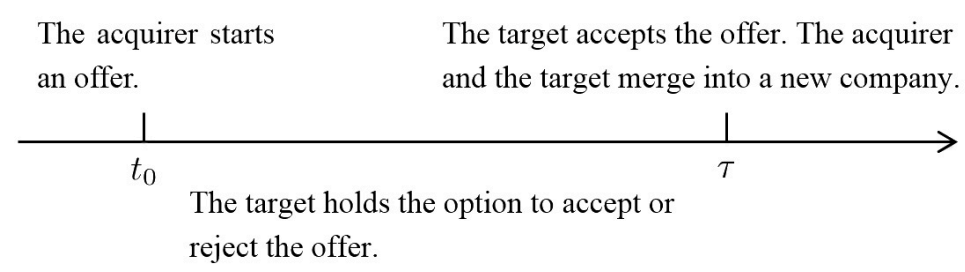

Figure 1: The acquisition process.

both the acquirer and the target of the merger.

The paper is organized as follows. In Section 2, we introduce the model's framework and provide a pure cash-payment model. In Section 3, we first develop a basic model with full information. We then extend the basic model to one with imperfect information in Section 3.2. In Section 3.3, we analyze the impact of the information on the results. In Section 4, we give several numerical examples. Finally, Section 5 concludes.

\section{The Model Set-up}

\subsection{Basic framework}

We construct the framework based on Morellec and Zhdanov [16]'s model. Consider two firms: an acquirer and a target, which operate in the same market. We assume capital stocks of $K_{B}$ for the acquirer and $K_{T}$ for the target. The stock market valuation of each firm, denoted by $S_{B}\left(X_{t}\right)$ and $S_{T}\left(Y_{t}\right)$, respectively, before takeover is

$$
S_{B}\left(X_{t}\right)=K_{B} X_{t}, \quad S_{T}\left(Y_{t}\right)=K_{T} Y_{t}
$$

where $X_{t}$ and $Y_{t}$ denote the per unit value of capital, which follows a geometric Brownian motion, given by

$$
\begin{aligned}
\mathrm{d} X_{t} & =\mu_{X} X_{t} \mathrm{~d} t+\sigma_{X} X_{t} \mathrm{~d} W_{X}, \\
\mathrm{~d} Y_{t} & =\mu_{Y} Y_{t} \mathrm{~d} t+\sigma_{Y} Y_{t} \mathrm{~d} W_{Y},
\end{aligned}
$$

where expected growth rates $\mu_{X}, \mu_{Y}>0$, and volatilities $\sigma_{X}, \sigma_{Y}>0$ are constant parameters. $W_{X}$ and $W_{Y}$ are standard Brownian motions. The correlation coefficient between $W_{X}$ and $W_{Y}$ is constant, represented as $\rho \in(-1,1)$. We assume that all participants are risk neutral, and the risk-free interest rate is $r\left(\geq \mu_{i}, i=X, Y\right)$.

As shown in Figure 1, we suppose the acquisition process proceeds in two steps. At time $t_{0}$, the acquirer makes an offer to acquire the target. The target firm need not decide immediately upon receiving the offer, that is, it can postpone the decision. Hence, the target holds the option to accept or reject the offer from time $t_{0}$ onwards. The horizon of the option which the target holds is infinite. The acquirer is not looking for an immediate merger, which is generally associated with a higher cost. See Offenberg and Pirinsky [18] for the supporting evidence. Suppose the target accepts the offer at time $\tau$. Accepting the offer leads to an immediate merger of the two firms at time $\tau$. 
Following Hackbarth and Morellec [8] and Shleifer and Vishny [19], we assume a linear combination of pre-takeover values in terms of per unit value of capital. The post-merger value of the firm is

$$
S_{M}\left(X_{t}, Y_{t}\right)=S_{B}\left(X_{t}\right)+S_{T}\left(Y_{t}\right)+G\left(X_{t}, Y_{t}\right),
$$

where $G\left(X_{t}, Y_{t}\right)$ is net synergy gains generated from the merger, given by

$$
G\left(X_{t}, Y_{t}\right)=K_{T}\left(\alpha\left(X_{t}-Y_{t}\right)-c Y_{t}\right), \quad(\alpha, c) \in \mathbb{R}_{++}^{2},
$$

where $\alpha$ is the synergy parameter, which all participants can observe. $c$ denotes the per unit merger cost of the capital value of the target firm. The post-merger per unit value of capital which the target has before merger changes to $\alpha X_{t}+(1-\alpha) Y_{t}$. Therefore, the post-merger value of the target's capital increases to $S_{T}\left(Y_{t}\right)+K_{T} \alpha\left(X_{t}-Y_{t}\right)$. Considering the cost paid at the time of the merger, the synergy generated thus is given by (4). This assumption indicates that the synergy will be positive only when the acquirer outperforms the target, which has the same meaning as $X_{t}>Y_{t}$. This is equivalent to saying that the acquirer generally has a higher Tobin's q than the target. Raua and Vermaelen [20] provide the supporting evidence. The target's resources are more efficiently allocated after the merger.

\section{$2.2 \quad$ A Pure Cash-payment Model}

In this section, we develop a pure cash-payment model and will compare it with a mixed-payment model in the numerical examples section. For a pure cash-payment M\&A, the acquirer pays an amount of cash to the target based on the target's market value and buys the whole firm. There is no share exchange in the process. The acquirer is the only shareholder of the merged firm. Suppose the acquirer will use parts of their firm's value, which is denoted as portion $p$, to pay the cash payment. Receiving the offer at $t_{0}$, the target decides the timing to accept the offer according to the benefits generated. The optimization function for the target is

$$
O M^{c}\left(X_{t}, Y_{t}\right)=\max _{\tau^{c}} \mathbb{E}\left\{\mathrm{e}^{-r \tau^{c}}\left[p S_{B}\left(X_{\tau^{c}}\right)-S_{T}\left(Y_{\tau^{c}}\right)\right]\right\} .
$$

At time $\tau^{c}$, the target receives the offer. They will receive a cash payment, worth $p S_{B}\left(X_{\tau^{c}}\right)$ and give up their claim, worth $S_{T}\left(Y_{\tau^{c}}\right)$. Maximizing the function (5) yields Lemma 1.

Lemma 1 (The optimal threshold under a pure cash-payment method) Based on the valuemaximizing strategy, the target firm will accept the offer and merge with the acquirer when the ratio of per unit capital price, denoted by $R_{t}=X_{t} / Y_{t}$, reaches the level

$$
R_{\tau^{c}}=\frac{\vartheta_{1}}{\vartheta_{1}-1} \frac{K_{T}}{K_{B}} \frac{1}{p}
$$

Value of the option that the target holds is given by

$$
O M^{c}\left(X_{t}, Y_{t}\right)= \begin{cases}Y_{t}\left[p K_{B} R_{\tau^{c}}-K_{T}\right]\left(\frac{R_{t}}{R_{\tau^{c}}}\right)^{\vartheta_{1}}, & R_{t}<R_{\tau^{c}} \\ Y_{t}\left[p K_{B} R_{t}-K_{T}\right], & R_{t} \geq R_{\tau^{c}}\end{cases}
$$

and the first passing time is

$$
\tau^{c}=\inf \left\{t>0 \mid R_{t} \geq R_{\tau^{c}}\right\} .
$$


$\vartheta_{1}>1$ is the positive root of the quadratic equations

$$
\left(\frac{1}{2} \sigma_{X}^{2}+\frac{1}{2} \sigma_{Y}^{2}-\rho \sigma_{X} \sigma_{Y}\right) \vartheta(\vartheta-1)+\left(\mu_{X}-\mu_{Y}\right) \vartheta-\left(r-\mu_{Y}\right)=0 .
$$

Appendix A contains the proof.

As soon as the target accepts the offer, the two participating firms will merge. The acquirer gives up the claim, worth $S_{B}\left(X_{\tau^{c}}\right)$, and pays a cash amount of $p S_{B}\left(X_{\tau^{c}}\right)$ to the target at time $\tau^{c}$. In return, the acquirer receives ownership of the merged firm, worth $S_{M}\left(X_{\tau^{c}}, Y_{\tau^{c}}\right)$. The optimization function for the acquirer thereafter is given by

$$
O T^{c}\left(X_{t}, Y_{t}\right)=\max _{p} \mathbb{E}\left\{\mathrm{e}^{-r \tau^{c}}\left[S_{M}\left(X_{\tau^{c}}, Y_{\tau^{c}}\right)-p S_{B}\left(X_{\tau^{c}}\right)-S_{B}\left(X_{\tau^{c}}\right)\right]\right\}
$$

Lemma 2 (Optimal cash payment in a pure cash-payment model) Maximizing the payoff function (10) yields the optimal offered portion $p$ for the acquirer, given as

$$
p=\frac{\alpha\left(\vartheta_{1}-1\right)}{(\alpha+c-1)\left(\vartheta_{1}-1\right)+\vartheta_{1}} \frac{K_{T}}{K_{B}} .
$$

Substituting result (11) into (6) yields

$$
R_{\tau^{c}}=\frac{\vartheta_{1}}{\vartheta_{1}-1} \frac{1}{\alpha}\left(\alpha+c-1+\frac{\vartheta_{1}}{\vartheta_{1}-1}\right)
$$

Appendix B contains the proof.

According to (6), the higher $p$ is, the lower the threshold will be. The merging process will be accelerated if the acquirer uses a high portion $p$ of the combined firm value to pay the target. If the acquirer chooses an optimal portion $p$, which is given by (11), the target will accept the offer when the ratio of per unit capital value $R_{t}$ reaches (48). If both of the participating firms use their optimal strategies, the threshold of merging is independent of the cash payment portion $p$.

\section{A Mixed-payment Model}

In a stock-for-stock $\mathrm{M} \& \mathrm{~A}$, the acquirer and target generally determine the post-merger terms according to the ratio of their firm's market values. In a mixed-payment model, the acquirer aims to hold a certain fraction of the merged firm in order to partly control or proportionally enjoy the business of the new firm. If the terms the acquirer asks for are higher than the terms in the stock-for-stock M\&A, the acquirer has to pay a cash acquisition premium to the target in order to get a higher share. On the other hand, the acquirer will ask for a cash acquisition premium from the target if the post-merger terms are low. We use parameter $\lambda$ to denote the cash acquisition premium payment. This means that the acquirer will pay $\lambda S_{T}\left(Y_{t}\right)$ to the target, where $S_{T}\left(Y_{t}\right)$ is the pre-merger market value of the acquired firm, given by (1). The acquirer will receive terms $\xi(>0)$ of the merged entity in return. Consequently, the target gets a cash acquisition premium payment of $\lambda S_{T}\left(Y_{t}\right)$ and receives $(1-\xi)$ as the fraction of the merged firm. The parameter $\lambda$ can even be negative, in which case, the target shareholders bargain for a higher post-merger ownership than the fraction they could get without the 
cash payment. The acquirer asks the target to pay for the higher share. There is also the need to pay the transaction costs, denoted as $c S_{T}\left(Y_{t}\right)$, when the merging of firms occurs.

From the target's standpoint, the higher the $\lambda S_{T}\left(Y_{t}\right)$ is, the higher the cash acquisition premium payment they will receive upon selling. On the other hand, the fraction of ownership will decrease, and the target will therefore receive a lower share $(1-\xi)$. From the acquirer's perspective, if they provide a higher payment to the target, the cost will increase, though they will also gain a higher fraction $\xi$ of the new entity. Therefore, there is an optimal payment strategy and terms (also called sharing-rule) $\xi$ for both the acquirer and target.

As shown in Figure 1, at time $t_{0}$, the acquirer offers a certain cash acquisition premium payment $\lambda$ to the target, which can accept or reject the offer. At time $\tau$, the target firm receives a cash acquisition premium payment of $\lambda S_{T}\left(Y_{\tau}\right)$ from the acquirer and a fraction $(1-\xi)$ of the merged firm, and in turn, has to give up a claim of $S_{T}\left(Y_{\tau}\right)$.

\subsection{A Mixed-payment Model in a Market with Perfect Information}

In this section, we consider a scenario with perfect information and no competition in the process. As illustrated in the framework, there are two stages in the merger process. We use the Markov Perfect Nash Equilibrium to analyze the strategy, in which the acquirer will provide an optimised cash acquisition premium payment of $\lambda$ at stage one. The target receives this offer in stage one with a given $\lambda$ and will accept the offer at the threshold of $\tau$ that maximizes their profit. The acquirer and target will bargain about the terms according to the optimised cash payment portion $\lambda$ and the threshold.

The target firm reacts to receiving the offer of the cash acquisition premium payment $\lambda$ in stage one. They hold the option of accepting the offer. Conditional on the offered cash payment portion $\lambda$, the target will choose a threshold $\tau$ in stage two and accept the offer. The cash acquisition premium payment to accept the offer is $\lambda S_{T}\left(Y_{\tau}\right)$. Therefore, the target will give up their claim, worth $S_{T}\left(Y_{\tau^{m}}\right)$, and receive both the cash payment value $\lambda S_{T}\left(Y_{\tau}\right)$ and a fraction $(1-\xi)$ of the merged firm, worth $(1-\xi) S_{M}\left(X_{\tau}, Y_{\tau}\right)$. The optimization function of the target at stage two is

$$
O M\left(X_{t}, Y_{t}\right)=\max _{\tau^{m}} \mathbb{E}\left\{\mathrm{e}^{-r \tau^{m}}\left[(1-\xi) S_{M}\left(X_{\tau^{m}}, Y_{\tau^{m}}\right)+\lambda S_{T}\left(Y_{\tau^{m}}\right)-S_{T}\left(Y_{\tau^{m}}\right)\right]\right\} .
$$

Lemma 3 (Optimal threshold for the target in stage two) Based on the value-maximizing strategy, if offered cash acquisition premium payment satisfies $\lambda<(1-\xi)(\alpha+c)+\xi$, the target firm will accept the offer and merge with the acquirer when the ratio of per unit capital price $R_{t}$ reaches the level

$$
R^{m}(\lambda, \xi)=\left((\alpha+c-1)+\frac{1-\lambda}{1-\xi}\right) \frac{\vartheta_{1}}{\vartheta_{1}-1} \frac{K_{T}}{K_{B}+\alpha K_{T}}
$$

The value of the option that the target holds is

$$
\begin{aligned}
& O M\left(X_{t}, Y_{t}\right)= \\
& \begin{cases}Y_{t}\left[\frac{(1-\xi)(\alpha+c-1)+(1-\lambda)}{\vartheta_{1}-1} K_{T}\right]\left(\frac{R_{t}}{R^{m}(\lambda, \xi)}\right)^{\vartheta_{1}}, & R_{t}<R^{m}(\lambda, \xi), \\
Y_{t}\left[(1-\xi)\left(K_{B}+\alpha K_{T}\right) R_{t}+((1-\xi)(1-\alpha-c)-(1-\lambda)) K_{T}\right], & R_{t} \geq R^{m}(\lambda, \xi) .\end{cases}
\end{aligned}
$$


The first passing time is

$$
\tau^{m}=\inf \left\{t>0 \mid R_{t} \geq R^{m}(\lambda, \xi)\right\} .
$$

And $\vartheta_{1}>1$ is the positive root of (9). Appendix $C$ provides the proof.

If the offered cash acquisition premium payment satisfies $\lambda \geq(1-\xi)(\alpha+c)+\xi$, the target will accept the offer immediately because of a high cash acquisition premium payment. Otherwise the target will wait until the ratio of capital price first reaches the threshold (14), which is a reaction function of the cash acquisition premium payment $\lambda$ and the bargain terms $(1-\xi)$. Holding $(1-\xi)$ constant, a higher $\lambda$ will decrease $R^{m}$ and accelerate the merger. The threshold also largely relies on the ratio of firm size, represented by $K_{B} / K_{T}$. If given a constant $\lambda$, a higher ratio of firm size $\left(K_{B} / K_{T}\right)$ will also accelerate the merger. While, $\lambda$ provided by the acquirer is also firm size $\left(K_{B} / K_{T}\right)$ dependent that we will analyze in the next stage.

At stage two, the acquirer will give up their claims, worth $S_{B}\left(X_{\tau^{m}}\right)$, and also pay the cash acquisition premium payment of $\lambda S_{T}\left(Y_{\tau^{m}}\right)$. In return, they will receive a fraction $\xi$ of the merged firm, worth $\xi S_{M}\left(X_{\tau^{m}}, Y_{\tau^{m}}\right)$. The acquirer will choose an optimal portion $\lambda$ to maximize their benefit in stage one. The optimization function for the acquirer is

$$
O T\left(X_{t}, Y_{t}\right)=\max _{\lambda^{m}} \mathbb{E}\left\{\mathrm{e}^{-r \tau^{m}}\left[\xi S_{M}\left(X_{\tau^{m}}, Y_{\tau^{m}}\right)-\lambda^{m} S_{T}\left(Y_{\tau^{m}}\right)-S_{B}\left(X_{\tau^{m}}\right)\right]\right\} .
$$

Maximizing the payoff function (17) yields the following result.

Proposition 1 (Optimal tender offer in stage one) Based on the value-maximizing strategy, the optimal cash acquisition premium payment $\lambda^{m}$ that the acquirer pays to the target is given as

$$
\lambda^{m}(\xi)=(\alpha+c)(1-\xi)+\xi+\frac{\vartheta_{1}(\alpha+c)(1-\xi)\left(K_{B}+\alpha K_{T}\right)}{(1-\xi) K_{B}-\alpha\left(\vartheta_{1}+\xi-1\right) K_{T}} .
$$

Substituting result (18) into (14) yields

$$
R^{m}(\xi)=\frac{\vartheta_{1}^{2}}{\vartheta_{1}-1} \frac{(\alpha+c) K_{T}}{\alpha\left(\vartheta_{1}+\xi-1\right) K_{T}-(1-\xi) K_{B}} .
$$

Receiving the optimal offer of $\lambda^{m}(\xi)$, the target firm will accept the offer when the ratio of per unit capital price $R_{t}$ satisfies (19). The acquirer will immediately merge with the target after the target accepts the offer. Appendix D contains the proof.

According the result from (18), $d \lambda^{m}(\xi) / d(1-\xi)<0$ (which is equivalent to $d \lambda^{m}(\xi) / d \xi>0$ ), the cash payment parameter $\lambda^{m}$ positively relates to the terms $\xi$. Hence, the acquirer is willing to pay a higher cash acquisition premium to the target for greater post-merger management control $\xi$. On the other hand, a target's higher $(1-\xi)$ requirement will decrease $\lambda^{m}$ and increase the $R^{m}$, slowing the merging process.

We suppose the acquirer and target will negotiate the post-merger terms at stage one. The postmerger terms is $\xi$ for the acquirer and $(1-\xi)$ for the target. Having the results (18) and (19), the payoffs for the acquirer and target which are given by (13) and (17) are reaction functions of the terms $\xi$. The acquirer and target will negotiate the terms $\xi$ in order to maximize the payoffs (13) and 
(17), which represent their benefits generated from the merger. We obtain the optimal $\xi$ using the Nash bargaining approach. Banerjee, Güçbilmez and Pawlina [3] develop a model of the optimal real options exercise using the Nash bargaining approach. Based on Banerjee, Güçbilmez and Pawlina [3], we set the optimization function as

$$
\Pi\left(X_{t}, Y_{t}\right)=\max _{\xi^{m}}\left[O T\left(X_{t}, Y_{t} ; \xi^{m}\right)\right]^{\beta}\left[O M\left(X_{t}, Y_{t} ; \xi^{m}\right)\right]^{1-\beta}
$$

where the bargain power parameter $\beta$ is subject to $\beta \in(0,1)$. Solving the maximization problem (20) yields the following.

Proposition 2 (Optimal bargain terms) The acquirer will pay the optimal offered portion $\lambda^{m}$ and expect to receive the optimal terms $\xi^{m}$ of the merged entity, where $\xi^{m}$ satisfies

$$
\xi^{m}=1-\frac{(1-\beta) \alpha K_{T}}{K_{B}+\alpha K_{T}}
$$

Receiving the optimal offered portion $\lambda^{m}$, the optimal strategy for the target is to require $\left(1-\xi^{m}\right)$ as a fraction of the merged entity and choose to accept the offer at $\tau^{m}$. The terms for the target are

$$
1-\xi^{m}=\frac{(1-\beta) \alpha K_{T}}{K_{B}+\alpha K_{T}}
$$

Appendix E provides the proof.

The optimal terms which is given by (21) under a Nash bargaining solution positively relates to the ratio of the firm size $\left(K_{B} / K_{T}\right)$. With a higher firm size $\left(K_{B} / K_{T}\right)$, the acquirer is willing to require a higher $\xi^{m}$.

\subsection{A Mixed-payment Model in a Market with Imperfect Information}

In this section, we analyze the strategy in a market with asymmetric information. In this scenario, it is possible for the market value of per unit capital to be misjudged. In contrast to assumption (4), the net synergy gains generated from the merger here are

$$
G\left(X_{t}, Y_{t}\right)=K_{T}\left(\alpha\left(\omega_{B} X_{t}-\omega_{T} Y_{t}\right)-c Y_{t}\right), \quad(\alpha, c) \in \mathbb{R}_{++}^{2},
$$

where $\omega_{B}>0$ and $\omega_{T}>0$ are information parameters. The market value of per unit capital is underestimated if $\omega_{i} \in(1, \infty),(i=B, T)$, and overestimated if $\omega_{i} \in(0,1$,$) . Morellec and Zhdanov$ [16] assume that the information parameter is only observable to the managers of participating firms and other market participants do not know this value. In this model, we assume that the information asymmetry exists between the acquirer and target. Therefore $\omega_{B}$ is only observable to the managers of the acquirer and $\omega_{T}$ is only observable to the managers of the target. Thus, managers know only the real value of their own firm. Additionally, managers cannot trade on their inside information due to legal prohibitions.

For the acquirer, the net synergy gains generated from the merger are

$$
G^{B}\left(X_{t}, Y_{t}\right)=K_{T}\left(\alpha\left(\omega_{B} X_{t}-Y_{t}\right)-c Y_{t}\right)
$$


$\omega_{T}$ is not observable to the acquirer, which believes that the target firm's market capital price is the real price. Based on the acquirer's information, the post-merger value of the combined firm should be

$$
S_{M}^{B}\left(X_{t}, Y_{t}\right)=S_{B}\left(X_{t}\right)+S_{T}\left(Y_{t}\right)+G^{B}\left(X_{t}, Y_{t}\right)
$$

For the target, the net synergy gains generated from the merger are

$$
G^{T}\left(X_{t}, Y_{t}\right)=K_{T}\left(\alpha\left(X_{t}-\omega_{T} Y_{t}\right)-c Y_{t}\right) .
$$

Based on the target firm's information, the post-merger value of the combined firm should be

$$
S_{M}^{T}\left(X_{t}, Y_{t}\right)=S_{B}\left(X_{t}\right)+S_{T}\left(Y_{t}\right)+G^{T}\left(X_{t}, Y_{t}\right)
$$

Asymmetric information will be disclosed after the merger. Therefore, the merger of the two firms will generate an abnormal return at the time of merger.

Similar to the model in the perfect information market, the optimization function of the reacting party (target firm) at stage two is

$$
O M^{i m}\left(X_{t}, Y_{t}\right)=\max _{\tau^{i m}} \mathbb{E}\left\{\mathrm{e}^{-r \tau^{i m}}\left[(1-\xi) S_{M}^{T}\left(X_{\tau^{i m}}, Y_{\tau^{i m}}\right)+\lambda S_{T}\left(Y_{\tau^{i m}}\right)-S_{T}\left(Y_{\tau^{i m}}\right)\right]\right\} .
$$

Lemma 4 (Optimal threshold in stage two in a market with imperfect information) If the offered cash acquisition premium payment satisfies $\lambda<\xi+\left(\alpha \omega_{T}+c\right)(1-\xi)$, the target firm will accept the offer and merge with the acquirer when the ratio of per unit capital value $R_{t}$ reaches

$$
R^{i m}(\lambda, \xi)=\left(\left(\alpha \omega_{T}+c-1\right)+\frac{1-\lambda^{i m}}{1-\xi^{i m}}\right) \frac{\vartheta_{1}}{\vartheta_{1}-1} \frac{K_{T}}{K_{B}+\alpha K_{T}} .
$$

The value of merger option for the target is

$$
\begin{aligned}
& O M^{i m}\left(X_{t}, Y_{t}\right)= \\
& \left\{\begin{array}{cc}
Y_{t}\left[\frac{(1-\xi)\left(\alpha \omega_{T}-c-1\right)+(1-\lambda)}{\vartheta_{1}-1} K_{T}\right]\left(\frac{R_{t}}{R^{i m}(\lambda, \xi)}\right)^{\vartheta_{1}}, & R_{t}<R^{i m}(\lambda, \xi), \\
Y_{t}\left[(1-\xi)\left(K_{B}+\alpha K_{T}\right) R_{t}+\left((1-\xi)\left(1-\alpha \omega_{T}-c\right)-(1-\lambda)\right) K_{T}\right], & R_{t} \geq R^{i m}(\lambda, \xi),
\end{array}\right.
\end{aligned}
$$

and the first passing time is

$$
\tau^{i m}=\inf \left\{t>0 \mid R_{t} \geq R^{i m}(\lambda, \xi)\right\} .
$$

$\vartheta_{1}>1$ is the positive root of (9). Appendix F provides the proof.

At stage one, the acquirer's optimization function, which is also similar to the model in the perfect information market, is

$$
O T^{i m}\left(X_{t}, Y_{t}\right)=\max _{\lambda^{i m}} \mathbb{E}\left\{\mathrm{e}^{-r \tau^{m}}\left[\xi S_{M}^{B}\left(X_{\tau^{m}}, Y_{\tau^{m}}\right)-\lambda^{i m} S_{T}\left(Y_{\tau^{m}}\right)-S_{B}\left(X_{\tau^{m}}\right)\right]\right\} .
$$

With the available information, the acquirer will estimate the target firm's threshold as $R^{m}\left(\lambda^{i m}, \xi\right)$, which is given by (14). After offering an optimal cash acquisition premium payment $\lambda^{i m}$, the acquirer will estimate that the target is willing to accept the offer when the ratio of per unit capital value $R_{t}$ reaches $R^{m}\left(\lambda^{i m}, \xi\right)$. While the real threshold that the target will choose is $R^{i m}\left(\lambda^{i m}, \xi\right)$, given by (29). We call the difference between the real threshold chosen by the target and the estimated threshold for the acquirer as information distortion. 
Proposition 3 (Optimal tender offer in stage one in a market with imperfect information) The information parameter $\omega_{T}$ is not observable before $\tau^{i m}$, the acquirer then optimises the acquisition premium under a distorted estimation due to information distortion. The optimal cash acquisition premium payment $\lambda^{i m}$ the acquirer chooses is

$$
\lambda^{i m}(\xi)=(1-\xi)(\alpha+c)+\xi+\frac{\vartheta_{1}(\alpha+c)(1-\xi)\left(K_{B}+\alpha K_{T}\right)}{(1-\xi) K_{B}-\alpha\left(\left(\vartheta_{1}+\xi-1\right)+\vartheta_{1} \xi\left(\omega_{B}-1\right)\right) K_{T}} .
$$

Given $\lambda^{i m}(\xi)$, the threshold finally is equal to $R^{i m}(\xi)$. According to the result of (29), the optimal threshold to accept the offer is

$$
R^{i m}(\xi)=\frac{\vartheta_{1}}{\vartheta_{1}-1}\left(\frac{\alpha\left(\omega_{T}-1\right) K_{T}}{K_{B}+\alpha K_{T}}+\frac{\vartheta_{1}(\alpha+c) K_{T}}{\alpha\left(\left(\vartheta_{1}+\xi-1\right)+\vartheta_{1} \xi\left(\omega_{B}-1\right)\right) K_{T}-(1-\xi) K_{B}}\right)
$$

Appendix G provides the proof.

Similar to the model in the perfect information market, we use the Nash bargain approach to derive the optimal bargain terms. The optimization function of the terms is

$$
\Pi^{i m}\left(X_{t}, Y_{t}\right)=\max _{\xi^{i m}}\left[O M^{i m}\left(X_{t}, Y_{t} ; \xi^{i m}\right)\right]^{\beta}\left[O T^{i m}\left(X_{t}, Y_{t} ; \xi^{i m}\right)\right]^{1-\beta}
$$

where the bargaining power parameter $\beta$ is subject to $\beta \in(0,1)$. Solving the maximization problem (35) yields the following result.

Proposition 4 (Optimal post-merger terms in a market with imperfect information) The acquirer will pay the optimal acquisition premium payment $\lambda^{i m}$ and expect to receive the optimal fraction $\xi^{i m}$ of the merged entity. For receiving the optimal offered portion $\lambda^{i m}$, the optimal strategy for the target is to require $\left(1-\xi^{i m}\right)$ as a fraction of the merged entity and choose to accept the offer at $\tau^{i m}$. The optimal merger terms in a market with imperfect information satisfies

$$
\frac{\alpha}{\alpha+c} \frac{K_{T}}{K_{B}+\alpha K_{T}} \frac{\omega_{B}}{1-\xi^{i m}}=\frac{\gamma_{1}}{\gamma_{2}^{2}}+\frac{(1-\beta) \gamma_{1}}{\beta \vartheta_{1} \gamma_{2}^{2}-(1-\beta)\left(1-\vartheta_{1}\right) \gamma_{1} \gamma_{2}}
$$

where

$$
\begin{aligned}
& \gamma_{1}=\left(1-\xi^{i m}\right)(\alpha+c-1)+\left(1-\lambda^{i m}\left(\xi^{i m}\right)\right) \\
& \gamma_{2}=\left(1-\xi^{i m}\right)\left(\alpha \omega_{T}+c-1\right)+\left(1-\lambda^{i m}\left(\xi^{i m}\right)\right) .
\end{aligned}
$$

Appendix $H$ provides the proof.

The entire strategy will be decided in stage one; therefore, both the participating firms have no chance to adjust the strategy after the decision made. The optimal terms under a Nash bargaining approach in the imperfect information market is the solution to (36). For the acquirer, the strategy will be $\left(\lambda^{i m}, \xi^{i m}\right)$. For the target, the strategy will be $\left(R^{i m}, 1-\xi^{i m}\right)$. In the next section, we analyze the impact of the information on the strategy. 


\subsection{Impact of Information}

All the hidden information is revealed after the entire merging process is complete. After merging, the market value reflects the real value of the enterprise. Before merging, the participating firms know only their own real value and estimate their counterpart's value assuming that their value is equal to the market value. Because the information parameter $\omega_{T}$ is unknown to the acquirer until after the merger, $\omega_{T}$ has no impact on the decision, which is the optimal cash acquisition premium payment $\lambda^{i m}$ for the acquirer. Comparing the results of (18) and (33), the higher the information parameter $\omega_{B}$ is, the higher the acquisition premium the acquirer will provide. In the range $\omega_{B} \in(0,1), \lambda^{i m}<\lambda^{m}$ and the reversal in the relationship occurs in the range $\omega_{B} \in(1, \infty)$.

Corollary 1 (Impact of information on the acquisition premium) The acquirer is willing to pay a higher acquisition premium if the target firm is underestimated, and versa lower one if it is overestimated. Therefore, a higher acquisition premium accelerates the merger process and the disclosure of underestimated information.

The target will choose its strategy by following the reaction function (29); the effect of information on their function is as follows.

Corollary 2 (Impact of information on the threshold) If the parameters satisfy

$$
(1-\xi) \alpha\left(\omega_{T}-1\right)>\lambda^{i m}-\lambda^{m},
$$

this is equivalent to

$$
\frac{\omega_{T}-1}{\omega_{B}-1}>\frac{\xi \vartheta_{1}^{2}(\alpha+c)\left(K_{B}+\alpha K_{T}\right) K_{T}}{\left((1-\xi) K_{B}-\alpha\left(\vartheta_{1}+\xi-1\right) K_{T}\right)\left((1-\xi) K_{B}-\alpha\left[\left(\vartheta_{1}+\xi-1\right)+\vartheta_{1} \xi\left(\omega_{B}-1\right)\right] K_{T}\right)},
$$

the threshold in the situation with imperfect information is higher than that with perfect information, which leads to

$$
R^{i m}>R^{m}
$$

If $\omega_{B} \in(0,1)$ and $\omega_{T} \in(1, \infty)$, the left side of (39) is positive and the right side is negative. Thus, the inequality (39) will always be satisfied. If $\omega_{B} \in(1, \infty)$ and $\omega_{T} \in(0,1)$, the inequality (39) will never be satisfied because of the different signs on the two sides. Therefore, if the target is overvalued and the acquirer is undervalued, or vice versa, the inequality (39) will never be satisfied. If inequality (39) cannot be satisfied, the condition $R^{i m}<R^{m}$ always holds. In this situation, the symmetric information will always accelerate the merger. On the other hand, if both the target and acquirer are overestimated, which leads to $\omega_{T} \in(0,1)$ and $\omega_{B} \in(0,1)$, inequality (40) means that the greater the overestimation of the target, the higher is the threshold. Additionally, if both the target and acquirer are underestimated, which leads to $\omega_{T} \in(1, \infty)$ and $\omega_{B} \in(1, \infty)$, inequality (40) means that the greater the underestimation of the target, the higher is the threshold. Therefore, if the misestimations of per unit market value of capital are in the same direction, the greater is the information distortion is and the slower the merger process will be. 
When the acquirer and target merge, they will receive a certain fraction of the merged firm under the real net synergy gain from merging, given by (23). We can write the pre-merger value of the acquirer as

$$
S_{B}\left(X_{\tau_{-}^{i m}}, Y_{\tau_{-}^{i m}}\right)=K_{B} X_{\tau_{-}^{i m}}+O T^{i m}\left(X_{\tau_{-}^{i m}}, Y_{\tau_{-}^{i m}} ;\left(\omega_{B}, 1\right)\right)
$$

In addition, the pre-merger value of the target is

$$
S_{T}\left(X_{\tau_{-}^{i m}}, Y_{\tau_{-}^{i m}}\right)=K_{T} Y_{\tau_{-}^{i m}}+O M^{i m}\left(X_{\tau_{-}^{i m}}, Y_{\tau_{-}^{i m}} ;\left(1, \omega_{T}\right)\right) .
$$

The abnormal returns satisfy

$$
\begin{aligned}
A R_{X}\left(X_{\tau^{i m}}, Y_{\tau^{i m}}\right) & =\frac{O T^{i m}\left(X_{\tau^{i m}}, Y_{\tau^{i m}} ;\left(\omega_{B}, \omega_{T}\right)\right)-O T^{i m}\left(X_{\tau^{i m}}, Y_{\tau^{i m}} ;\left(\omega_{B}, 1\right)\right)}{S_{B}\left(\tau_{-}^{i m}\right)}, \\
& =\frac{\xi \alpha\left(1-\omega_{T}\right) K_{T}}{\xi\left(K_{B}+\alpha \omega_{B} K_{T}\right) R^{i m}+\left(\xi(1-\alpha-c)-\lambda^{i m}\right) K_{T}} . \\
A R_{Y}\left(X_{\tau^{i m}}, Y_{\tau^{i m}}\right) & =\frac{O M^{i m}\left(X_{\tau^{i m}}, Y_{\tau^{i m}} ;\left(\omega_{B}, \omega_{T}\right)\right)-O M^{i m}\left(X_{\tau^{i m}}, Y_{\tau^{i m}} ;\left(1, \omega_{T}\right)\right)}{S_{T}\left(\tau_{-}^{i m}\right)}, \\
& =\frac{(1-\xi) \alpha\left(\omega_{B}-1\right) K_{T} R^{m}}{(1-\xi)\left(K_{B}+\alpha K_{T}\right) R^{i m}+\left((1-\xi)\left(1-\omega_{T} \alpha-c\right)+\lambda^{i m}\right) K_{T}} .
\end{aligned}
$$

In the next section, we examine the abnormal returns and compare the results with previous studies.

\section{$4 \quad$ Numerical Examples}

This section provides several numerical tests of the results. We first compare the pure cash-payment model and the mixed-payment model. Second, we examine the cash acquisition premium payment and the reaction threshold of merger changes with endogenous parameters. Third, we study the impact of the information asymmetry and provide insights into effect of information on the results. Finally, we study the abnormal returns in this model and compare them with those reported in Morellec and Zhdanov [16]. They find that acquiring firms earn low or negative abnormal returns, while target firms earn substantially positive abnormal returns around the announcement date of the takeover.

Table 1 summarizes the basic parameter values. We assume drifts of the acquirer and target are 0.035 and 0.02. It follows that the acquirer generally outperforms the target. The volatility of the acquirer and target are set to $20 \%$ and $30 \%$ which means the target has higher risk than the acquirer. We focus on mergers of equal-size by assuming that $K_{B} / K_{T}=1$ and study the strategy of bargaining a high terms in order to have more management control. 
Table 1: Parameter values.

\begin{tabular}{lcl}
\hline \multicolumn{1}{c}{ Parameter } & & Value \\
\hline Expected growth rate of the acquirer & $\mu_{X}$ & 0.035 \\
Expected growth rate of the target & $\mu_{Y}$ & 0.02 \\
Volatility of the acquirer & $\sigma_{X}$ & 0.20 \\
Volatility of the target & $\sigma_{Y}$ & 0.30 \\
Ratio of the firm size & $K_{B} / K_{T}$ & 1.00 \\
Correlation coefficient & $\rho$ & 0.50 \\
Synergy parameter & $\alpha$ & 0.80 \\
Per unit merger cost & $c$ & 0.01 \\
Risk-free rate & $r$ & 0.06 \\
\hline
\end{tabular}

\subsection{Comparison between Pure Cash-payment Model and Mixed-payment Model}

In a pure cash-payment model, the threshold for the target is given by (6). Accordingly, the cashpayment portion in the pure cash-payment model, which is always constant, is given by

$$
\lambda^{c}=\frac{p K_{B} X_{\tau^{c}}}{K_{T} Y_{\tau^{c}}}=\frac{\vartheta_{1}}{\vartheta_{1}-1},
$$

which means that at the time the target accepts the offer, the acquirer will pay a cash amount of $\lambda^{c} S_{T}\left(Y_{\tau^{c}}\right)$ to the target in order to buy it completely. In the mixed-payment model, the acquirer will pay a cash acquisition premium amount of $\lambda^{m} S_{T}\left(Y_{\tau^{m}}\right)$ and receive the terms which satisfies $\xi \in(0,1]$ at $\tau^{m}$. To compare the performance of two payment methods, we need compare the payoff generated. In the mixed-payment model, the payoff for the acquirer $O T\left(X_{t}, Y_{t}\right)$ is given by $(17)$. $O T^{c}\left(X_{t}, Y_{t}\right)$, which is given by (10), is the payoff for the acquirer if the pure cash-payment method is used. We define the ratio of the payoff of the two payment methods as

$$
\Gamma=\frac{O T\left(X_{t}, Y_{t}\right)}{O T^{c}\left(X_{t}, Y_{t}\right)}
$$

If $\Gamma>1$, the mixed-payment method outperforms the pure cash-payment method, it is better to give up a portion of terms, which is equal to $(1-\xi)$, and use the mixed-payment method.

Figure 2 represents the ratio of the payoff which is given by (47). We assume that the acquirer asks for $80 \%$ management control in the merged firm $(\xi=0.8)$ if they use a mixed-payment method. In Figure 2, $\Gamma>1$ means payoff is higher if the acquirer gives up $20 \%$ management control of the merged firm and therefore use a mixed-payment method. $\Gamma$ decreases with the drift of the acquirer. The mixedpayment method outperforms the pure cash-payment method when $\mu_{X}$ is low and underperforms the pure cash-payment method when $\mu_{X}$ is high. The acquirer is willing to buy the whole firm of the target when the growth rate of the acquirer's core business is high because of a higher business benefits under the complete management control. By contrast, an increase in the growth rate of the target, which is $\mu_{y}$, leads to an increase in $\Gamma$. The higher the growth rate $\mu_{y}$ is, the more beneficial the mixed-payment method is. The acquirer will choose the pure cash-payment method when the risks of the core business of the acquirer itself or the target are high. When one of the participating firms faces high risks, a pure cash-payment method helps to distribute the risk because of an efficient allocation of the resources of the merged firm under complete management control. $\Gamma$ increases with the correlation coefficient 
Mergers and Acquisitions Strategy under Imperfect Information: A Mixed-payment Model
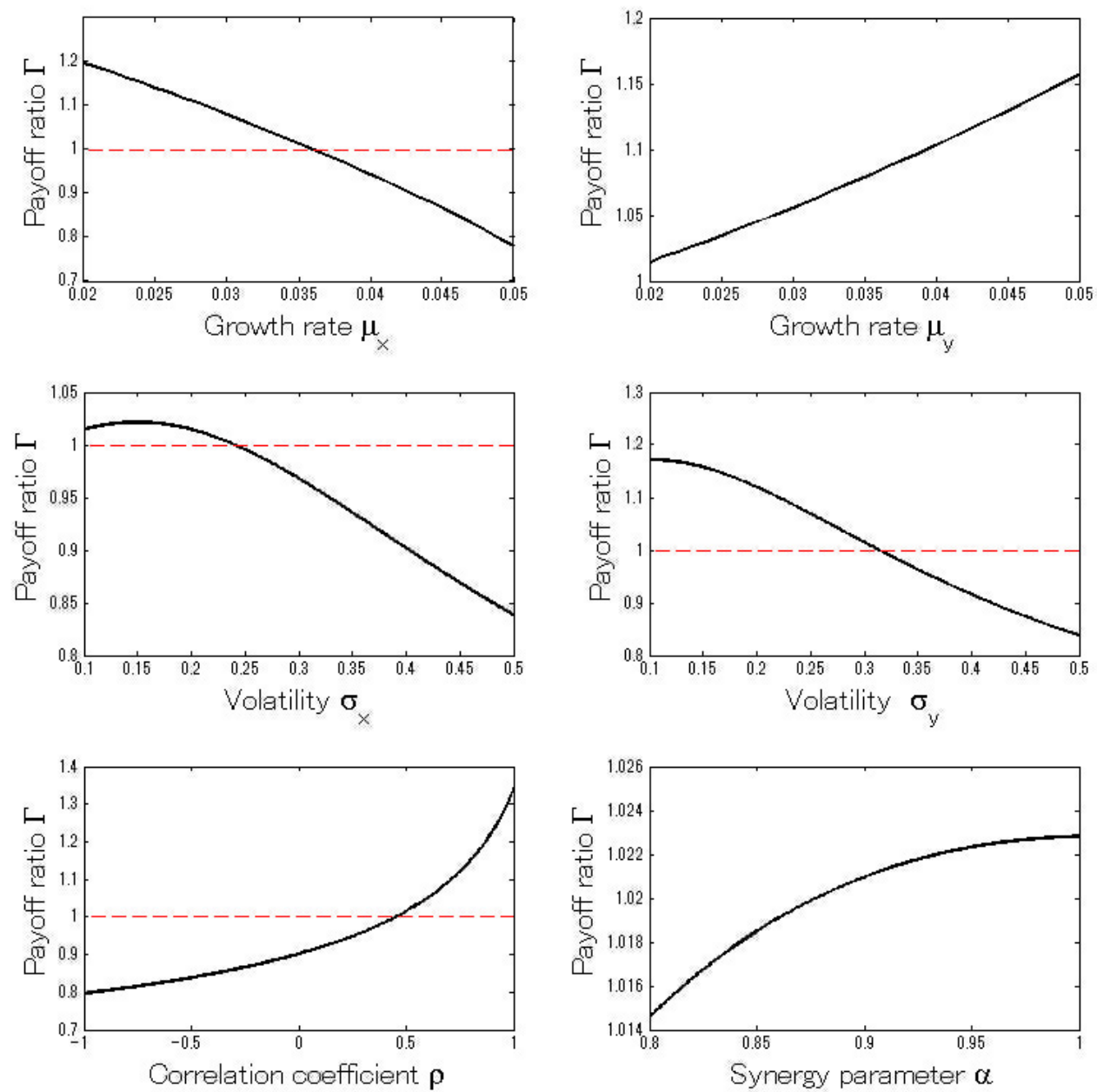

Figure 2: The ratio of the payoff using a mixed-payment method and using a pure cash-payment method under $\xi=0.8$. The dashed line represents $\Gamma=1$. 

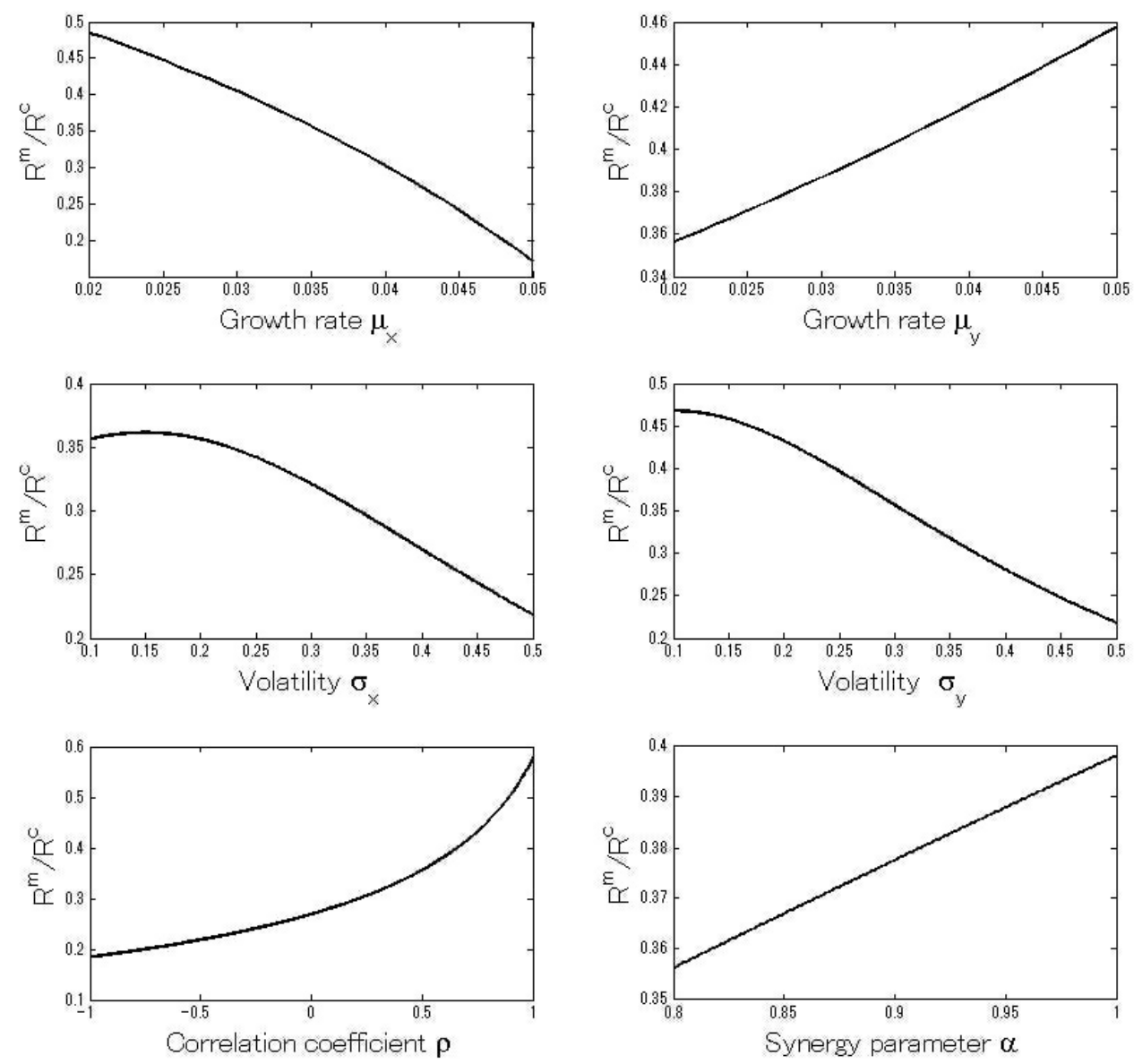

Figure 3: The comparison of the threshold of a mixed-payment method and a pure cash-payment method under $\xi=0.8$.

$\rho$. Therefore the mixed-payment method is better than the pure cash-payment method when $\rho$ is low because of the diversification of the core business of the two firms. $\Gamma$ increases with the synergy parameter $\alpha$. Recall that the synergy gain, which is given by the assumption (4), increases with $\alpha$. In the situation when $\alpha$ is high, the acquirer needs to pay more under a pure cash-payment method because the acquirer expects $100 \%$ management control and enjoys all the synergy gain.

The vertical axis of Figure 3 is $R^{m} / R^{c} . R^{m}$ is the threshold in the mixed-payment model, which is given by (14) in Lemma 3. $R^{c}$, which is given by (6) in Lemma 1 is the threshold in the pure cash-payment model. The execution speed of the mixed-payment method is greater than that of the pure cash-payment method if $R^{m} / R^{c}<1$. A higher threshold means the targets will demand a larger profits upon selling their assets before they make the decision. Figures 3 and 2 represents a similar relationships. When $R^{m} / R^{c}$ decreases, the execution speed of the mixed-payment method increases and the payoff of the mixed-payment method decreases, compared with the pure cash-payment method. Therefore, the acquirers need to find a trade-off between the execution speed benefits and the synergy 

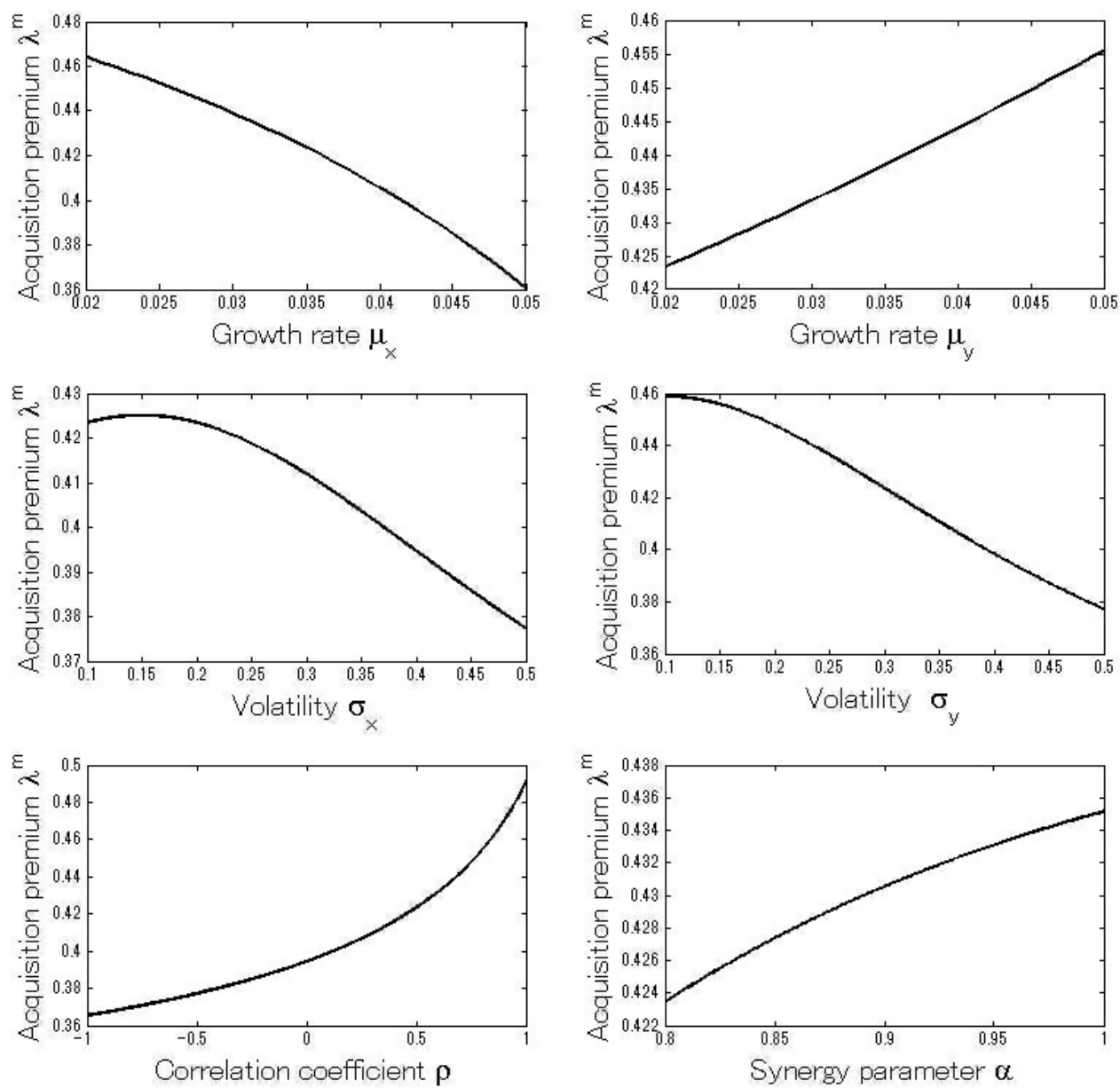

Figure 4: Parameter impacts on the acquisition premium $\lambda^{m}$ under $\xi=0.8 . \lambda^{m}$ is given by Proposition 1 . We assume that the acquirer will negotiate for a high share and test the cash acquisition premium with the growth rate, volatility, correlation coefficient, and synergy parameter.

generated when they choose a mixed-payment method.

\subsection{Relationship between Core Business Parameters and Decision Making}

The merger's timing and acquisition premium depend on the growth rate and volatility of the firms' core business valuations. We release the basic parameter values, which we want to test, and fix the others, as in Table 1.

In Figure 4, we find that the acquirer will pay a lower acquisition premium when the acquirer's growth rate is higher, and pay more when the target's growth rate is higher. According to Proposition $1, \partial \lambda^{m} / \partial \vartheta_{1}>0$ and parameter $\vartheta_{1}$, which is given by (9), hold a negative relationship with $\mu_{X}$. Hence, the cash payment portion $\lambda^{m}$ is negatively related to the growth rate $\mu_{X}$. Because $\partial \vartheta_{1} / \partial \mu_{Y}>0$, the target's growth rate is positively related to the cash payment portion $\lambda^{m}$. As in 

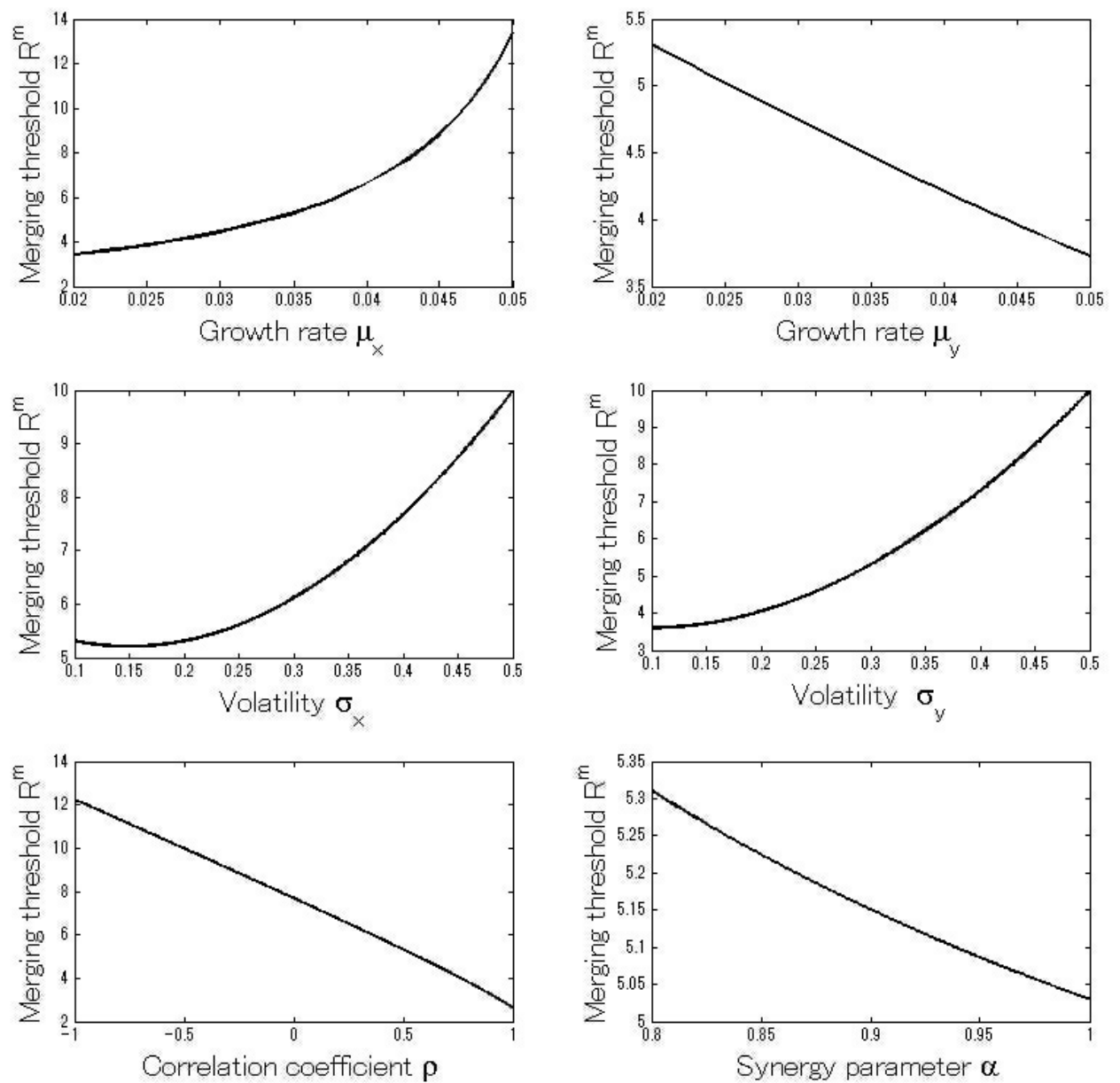

Figure 5: Parameter impacts on the threshold $R^{m}$ under $\xi=0.8 . R^{m}$ is given by Lemma 3. We again assume that the acquirer will negotiate for a high share and test the acquisition premium with the growth rate, volatility, correlation coefficient, and synergy parameter. 
the reaction function (29), the lower the acquisition premium is, the higher the threshold will be. Therefore, in Figure 5, an acquirer's higher growth rate will decelerate the merger process, and a target's higher growth rate will accelerate it.

In Figure 4, synergy parameter $\alpha$ will also increase the cash acquisition premium. According to the synergy assumption (4), the synergy generated due to merger is positively related to the synergy parameter $\alpha$. The acquirer is willing to pay a higher cash acquisition premium because of a high synergy when $\alpha$ is high.

When the volatility of both firms is high, the acquirer will pay a lower acquisition premium. Hence, it represent a reverse relationship in Figure 5. The parameter $\vartheta_{1}$ has a positive relationship with volatility $\sigma_{X}$ when $\sigma_{X}<\rho \sigma_{Y}$, and a positive relationship with volatility $\sigma_{X}$ when $\sigma_{X}>\rho \sigma_{Y}$. Thus, the acquisition premium will, at first, increase with volatility $\sigma_{X}$ and then decrease if $\rho>0$. If $\rho \leq 0, \sigma_{X}$ will always negative relates to $\vartheta_{1}$ and then also negative with $\lambda^{m}$. The red line represents $\rho=0.99$ in Figure 6, the maximum of $\lambda^{m}$ is given when $\sigma_{X}=\rho \sigma_{Y}$. Because we set $\sigma_{Y}=0.3$, as in Table $1, \lambda^{m}$ is maximized when $\sigma_{X}=0.297$ on the red line of Figure 6 and the threshold $R^{m}$ is minimised at the same point. The same relationship holds between $\lambda^{m}, R^{m}$ and $\sigma_{Y}$. The lower the correlation coefficient $\rho$ is, the less sensitive is the relation between volatility and the cash acquisition premium payment $\lambda^{m}$, according to Figure 6 . The lower the correlation coefficient $\rho$ is, the more sensitive is the relation between volatility and the threshold. As shown in Figures 4 and 5, an increase in correlation coefficient $\rho$ leads to an increase in the cash acquisition premium payment $\lambda^{m}$ and a decrease in the threshold.

In Figure 7, The ratio of the two participating firms always decreases the acquisition premium. Assuming a constant $K_{B}, K_{T}$ decreases when $K_{B} / K_{T}$ increases. Therefore, a comparatively smaller target will generate a small synergy, according to the assumption in (4). The acquirer will thereafter pay a lower cash acquisition premium. The threshold $R^{m}$ is a reaction function of the acquisition premium $\lambda^{m}$, which is given by Lemma 3; therefore, a lower $\lambda^{m}$ will increase the threshold and decelerate the process. As (19) in Proposition 1, the threshold $R^{m}$ positive relates to $K_{B} / K_{T}$. The target has two sources of returns: the cash premium payment $\lambda K_{T} Y_{\tau^{m}}$, which decreases with an increase in $K_{B} / K_{T}$, assuming a constant $K_{B}$; and the share payment $(1-\xi) S_{M}\left(X_{\tau^{m}}, Y_{\tau^{m}}\right)$, which also decreases because of a smaller synergy and thus a smaller $S_{M}\left(X_{\tau^{m}}, Y_{\tau^{m}}\right)$. A lower return decelerates the decision of accepting the offer and merger with the acquirer.

In Figure 8, if the acquirer negotiates a higher post-merger share $\xi$, it needs to pay a higher acquisition premium. The result follows Proposition 1. According to (18) in Proposition 1, the cash acquisition premium payment $\lambda^{m}$ is positively related to terms $\xi$ because $d \lambda^{m}(\xi) / d \xi>0$. The acquirer may expect more management control after the merger and will provide the target with an additional cash payment to attain it. The target firm is willing to receive a higher cash payment; therefore, the merger threshold is also lower when $\xi$ is higher. In the case of a small value of $\xi$, the acquiring firm is likely to receive lower business benefits after the merger because it has less management control in the target firm. The acquirer may even ask for cash compensation, which means $\lambda^{m}<0$. Therefore, the merger threshold is higher if the target needs to pay a cash compensation. 

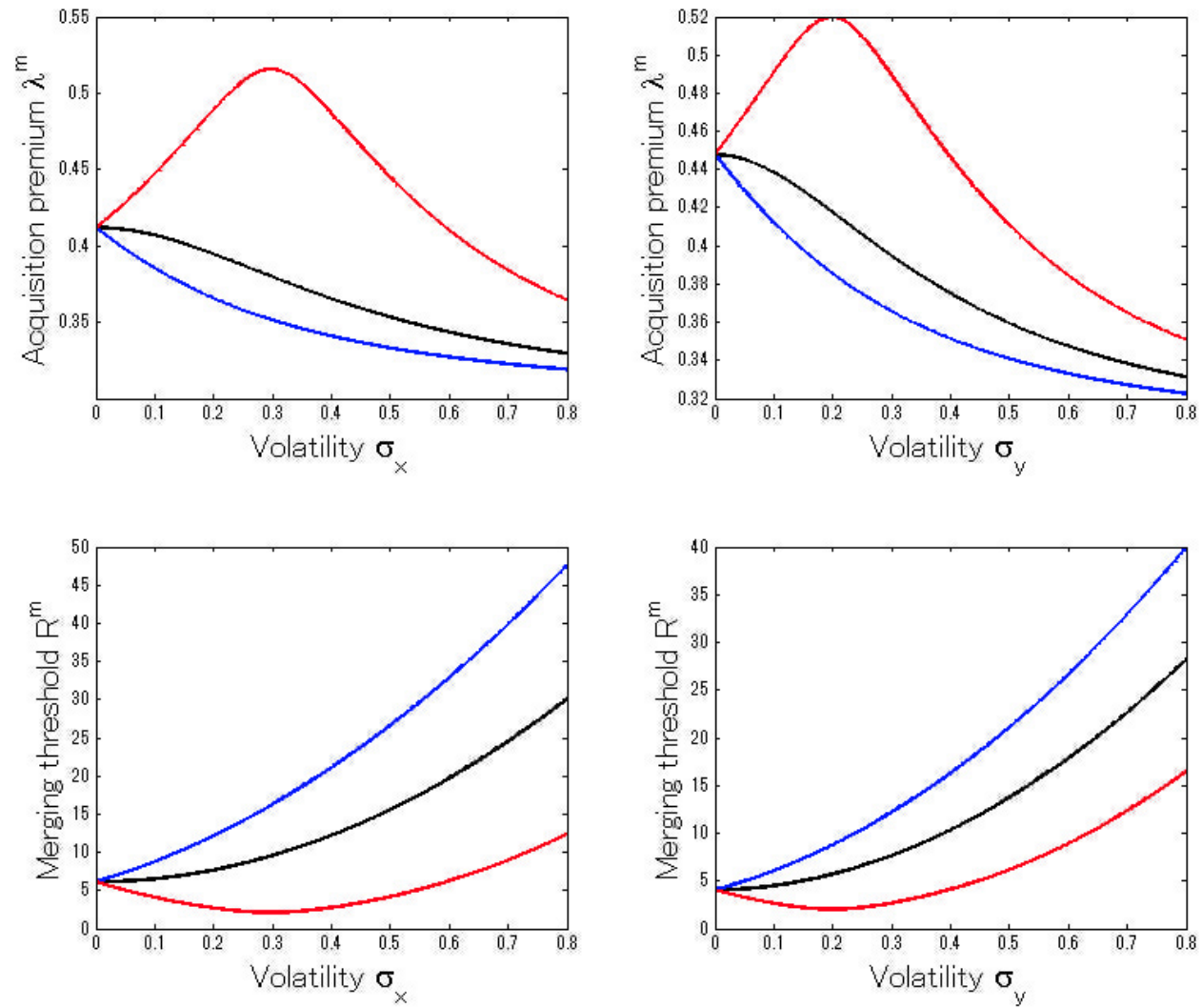

Figure 6: The impact of volatility on the cash acquisition premium and the threshold. The black, blue and red lines correspond to the following information premium: $\rho=0,-0.99$ and 0.99 .
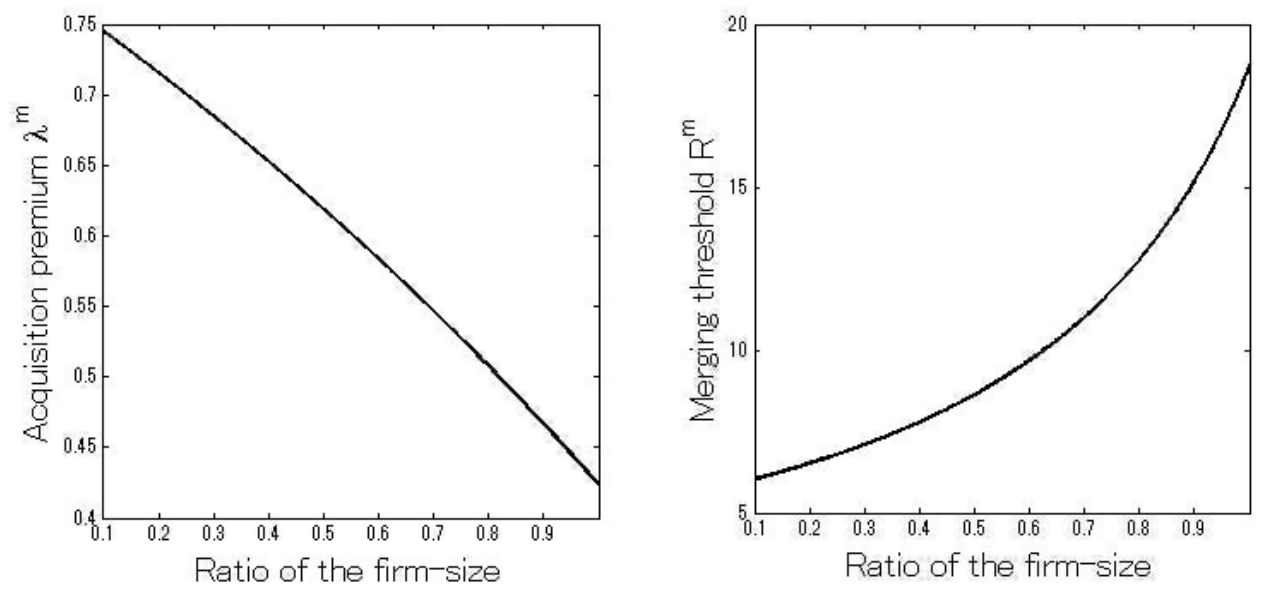

Figure 7: Effect of the firm size on strategy decision. firm size equals $K_{B} / K_{T}$. We assume $\omega_{T}=1$ and $\omega_{B}=1$ in this figure and test the impacts of firm size of the acquirer and target. Hence, the figure represents the relationship in a perfect information market. 

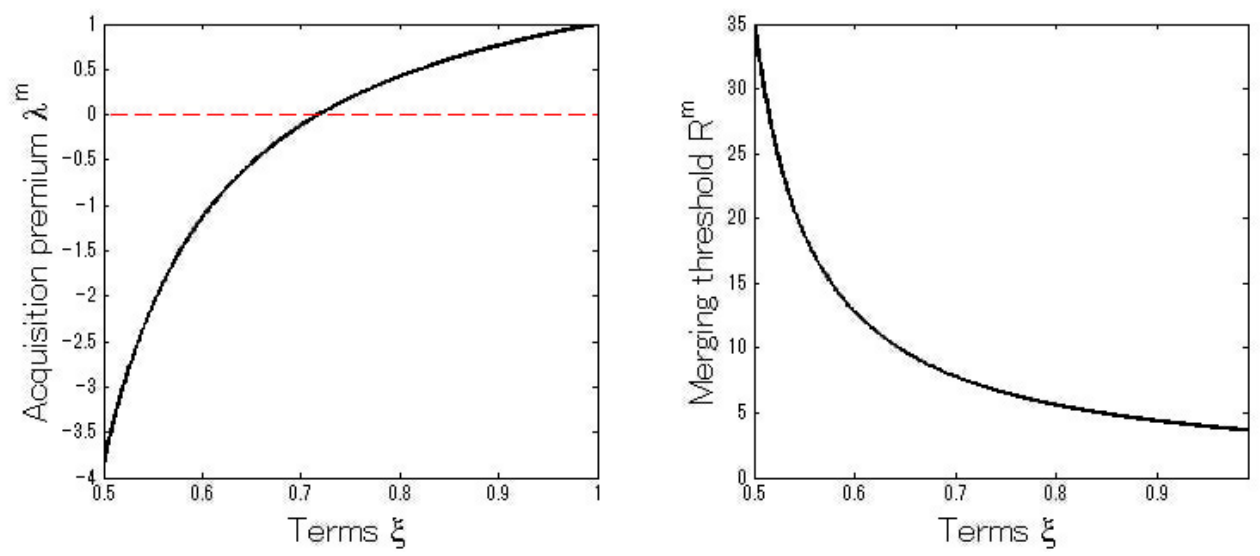

Figure 8: Relationship between the terms $\xi$, acquisition premium, and merger threshold. The left side represents the acquirer's strategy and we set $\omega_{T}=1$. The left side represents the target's strategy. Therefore, $\omega_{B}=1$.

\subsection{Information Impact}

In this section, we study the impact of information asymmetry on the cash acquisition premium payment $\lambda^{i m}$ and the threshold $R^{i m}$. We again release the basic parameter values, which we want to test, and fix the others, as in Table 1.

In Figure 9, an increase in the information parameter $\omega_{B}$ will increase the cash acquisition premium $\lambda^{i m}$. Recall that the acquirer is underestimated when $\omega_{B}>1$. Therefore the acquirer is willing to provide a higher $\lambda^{i m}$ when their firm is underestimated. This result follows Corollary 1 . In the situation $\xi=0.9$ which is represented as red line, the acquirer always pays a positive cash acquisition premium payment $\lambda^{i m}$ no matter the acquirer is overestimated or underestimated. The information asymmetry has less impact on $\lambda^{i m}$ when the acquirer bargains a high terms $\xi$ and has more impact when the terms $\xi$ is low. The acquirer will ask a cash payment from the target in the situation when the acquirer is overestimated and the bargain terms is low.

According to Corollary 2, the higher $\omega_{T}$ is, the easier the inequality (39) can be satisfied and the easier it is for the threshold in the imperfect information market to exceed that in the prefect information market. Therefore, $R^{i m}$ increases with the information parameter $\omega_{T}$, as shown in Figure 9.

In order to further study the impact on the cash acquisition premium. We give the definition of information premium as

$$
\Delta \lambda=\lambda^{i m}-\lambda^{m}
$$

where $\lambda^{i m}$ is given by (29) and $\lambda^{m}$ is given by (33). $\Delta \lambda$ represents the increment or decrement because of the information asymmetry between the acquirer and target.

Figure 10 represent the information premium $\Delta \lambda$ when the acquirer is underestimated and Figure 11 represent the information premium $\Delta \lambda$ when the acquirer is overestimated. $\Delta \lambda>0$ means the acquirer is willing to pay more because of the information asymmetry, and vice versa. Figures 10 and 11 also follow Corollary 1 as the result that the acquirer will provide a higher $\lambda^{i m}$ when their firm is underestimated a lower $\lambda^{i m}$ when their firm is overestimated. 

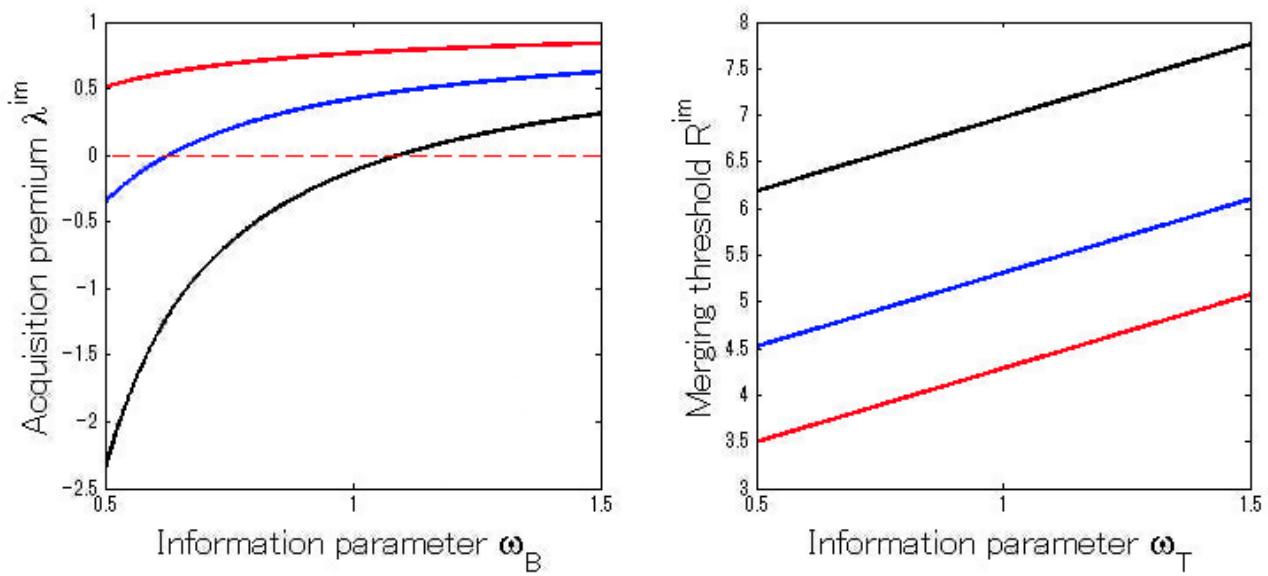

Figure 9: the impact of information asymmetry on the cash payment portion $\lambda^{i m}$ and the threshold $R^{i m}$ under the assumption of $\xi=0.8$. $\lambda^{i m}$ is given by Proposition 3 and $R^{i m}$ is given by Lemma 4 . The black, blue and red lines correspond to the following information premium: $\xi=0.7,0.8$ and 0.9 .

In Figure 10, the black line above the other two lines represents the situation $\omega_{B}=2$ which is also higher than other two information parameters set-up. It indicates that the acquirer is more likely to pay a higher cash acquisition premium in order to decrease the threshold $R^{i m}$ (which is provided in Lemma 4), and thereafter, accelerate the merger process. As a result, the acquirer is more willing to disclose the underestimated information.

Given a constant $\omega_{B}$, the growth rate $\mu_{X}$ increases the information premium and the growth rate $\mu_{Y}$ decreases the information premium, as shown in Figure 10. The higher the growth rate of the acquirer is, the more cash acquisition premium it will pay to accelerate the merger process, and therefore, accelerate the disclosure of the information. The volatility also increases the information premium in Figure 10. In Figure 4, the acquisition premium decreases with the volatility of both firms. As in Figure 10, the decrement of the acquisition premium when the acquirer is underestimated is smaller than that with prefect information. The acquisition premium is less sensitive to the volatility when the acquirer is underestimated. In Figure 4, the acquisition premium with perfect information increases with the correlation coefficient $\rho$. Figure 10 shows a decrease in information premium with an increase in the correlation coefficient $\rho$. The acquisition premium is less sensitive to $\rho$ when the acquirer is underestimated. Comparing Figures 10 and 11, we find that the information has great impact when the acquirer is overestimated.

\subsection{Imperfect Information and Abnormal Return}

Figure 12 plots the abnormal returns as a function of the information parameters $\omega_{B}$ and $\omega_{T}$. In the figures, the participating firms' abnormal returns can be positive or negative, according to the relationship between $\omega_{B}$ and $\omega_{T}$. Figure 12 shows a different result than that reported in Morellec and Zhdanov [16], in which the abnormal returns to the target shareholders are not always higher than those of the acquirer. The abnormal return to the target shareholders, which is given by (45), is largely influenced by $\omega_{B}$ and increases with $\omega_{B}$. The more the acquirer is underestimated, the more 
Mergers and Acquisitions Strategy under Imperfect Information: A Mixed-payment Model
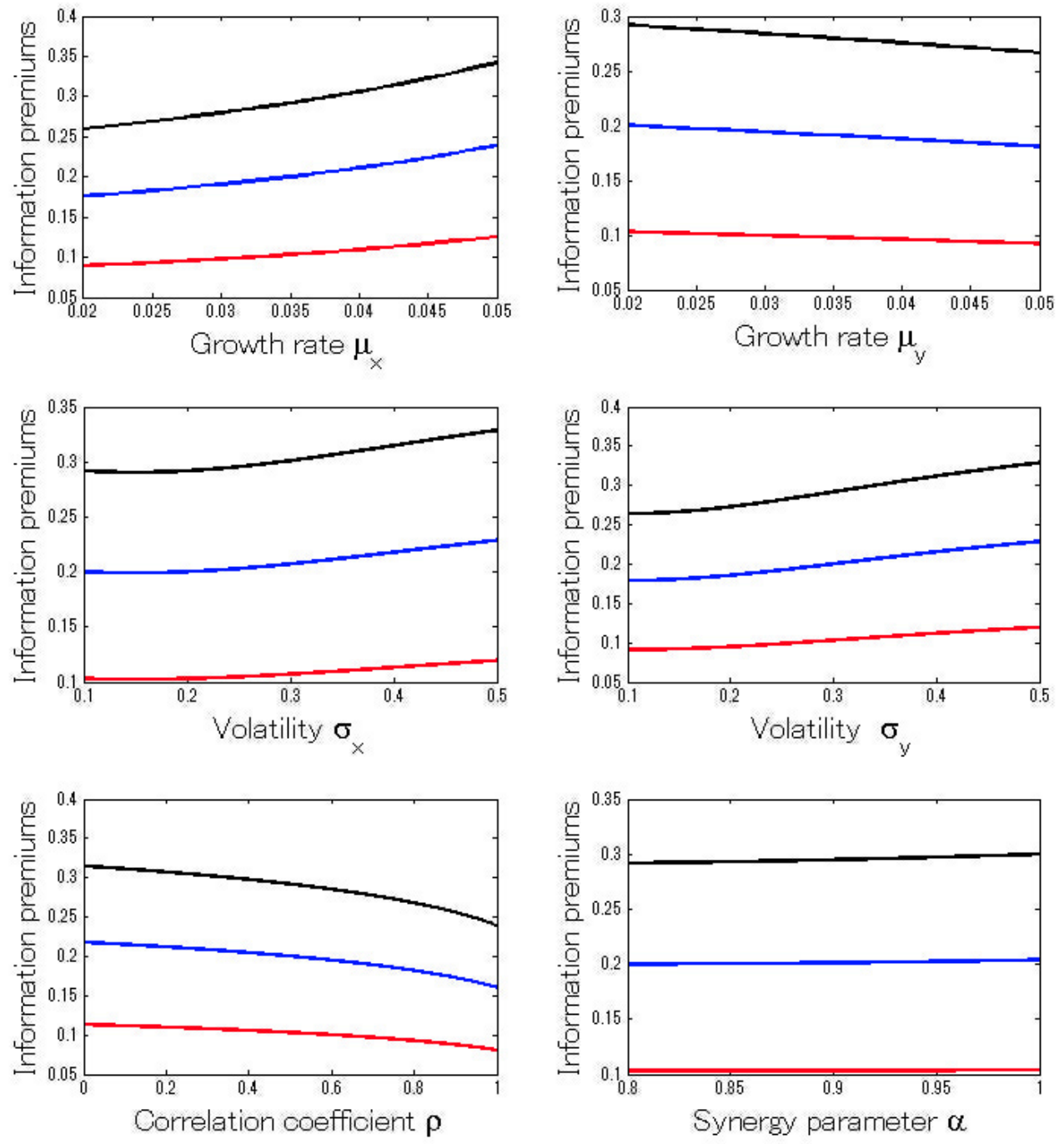

Figure 10: Information premium when the acquirer is underestimated. Assuming the post-merger terms $\xi=0.8$. The black, blue and red lines correspond to the following information premium: $\omega_{B}=2,1.5$ and 1.2 . 

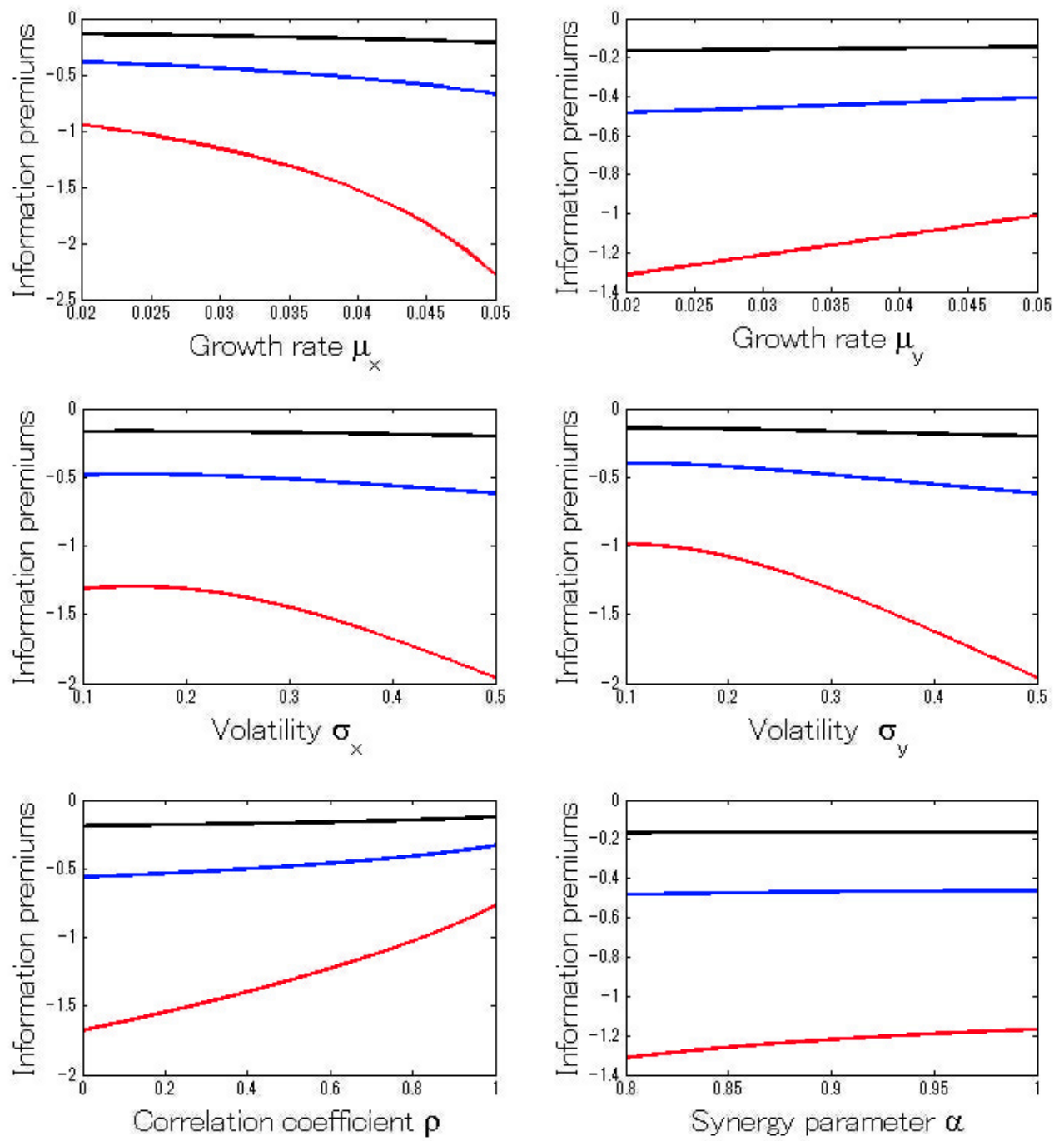

Figure 11: Information premium when the acquirer is overestimated. Assuming the post-merger terms $\xi=0.8$. The black, blue and red lines correspond to the following information premium: $\omega_{B}=0.8$, 0.6 and 0.4 . 
Mergers and Acquisitions Strategy under Imperfect Information: A Mixed-payment Model
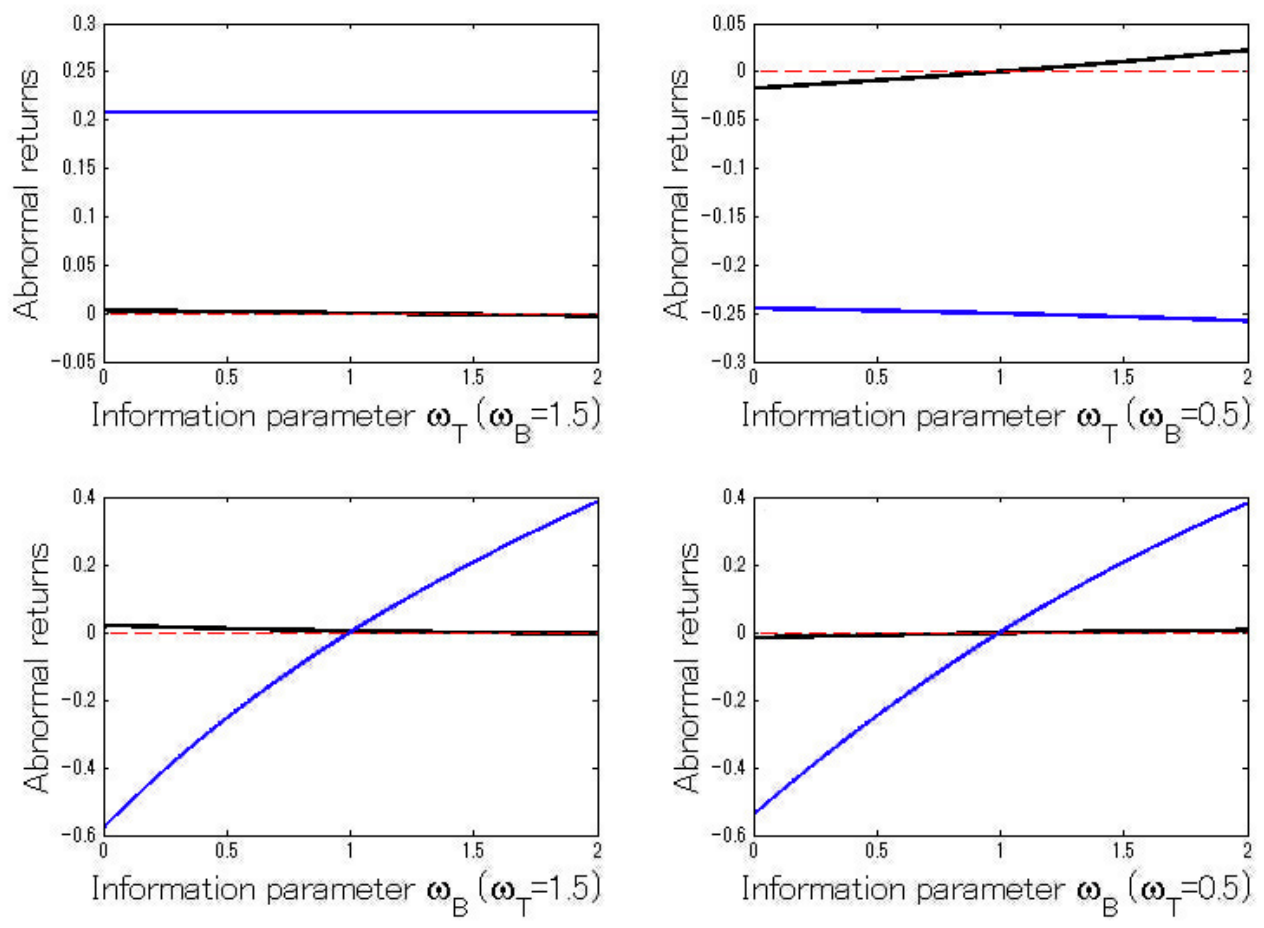

Figure 12: The effects of information on abnormal returns, given as (44) and (45). The black and blue lines represent the abnormal return of the acquirer and target, respectively. We first test the abnormal return change with the information parameter $\omega_{T}$, assuming $\omega_{B}=1.5$ and $\omega_{B}=0.5$, meaning that the acquirer is under- or over-estimated. We then test the abnormal return change with the information parameter $\omega_{B}$, assuming $\omega_{T}=1.5$ and $\omega_{T}=0.5$. 
the abnormal return to the target shareholders. The point of zero abnormal to the target shareholders is around $\omega_{B}=1$. The impact of $\omega_{T}$ was observable prior to the merger, and hence, has less impact on the target's abnormal return. The abnormal return to the acquirer shareholders, which is given by (44), is around zero and less influenced by the information parameter. The abnormal return to the acquirer is slightly influenced by $\omega_{T}$ and increases with $\omega_{T}$ when the acquirer is overestimated. For the acquirer, $\omega_{B}$ was observable before the merger, and thus, has less influence.

\section{Conclusion}

This paper develops a dynamic model of a joint takeover to determine the timing, acquisition premiums, and terms of a takeover. The model considers a mixed cash-share payment, with both acquisition premiums and a terms between the acquirer and target. We extend the model to a market with imperfect information and show how the strategy interacts with asymmetric information. The merger generates an abnormal return. The model also tests the relationship between the abnormal return and information parameters.

The timing, acquisition premiums, and terms of the takeover interact. The model predicts that (i) the mixed-payment method will outperforms the pure cash-payment method when the growth rate of the acquirer is high, the core business is low risky or the correlation coefficient of the participating company is low, (ii) the abnormal returns to the target's shareholders are negative when the acquirer is overestimated and positive when the acquirer is underestimated, (iii) the abnormal return to the target's shareholders can be higher or lower than those to the acquirer's shareholders, (iv) a higher acquisition premium will accelerate the merger process, and (v) an undervalued acquirer will accelerate the merger process and an underestimated target will decelerate the merger process.

\section{A Proof of Lemma 1}

According to Itô's lemma, the option value, $O M^{c}\left(X_{t}, Y_{t}\right)$, satisfies the partial differential equation

$$
\begin{aligned}
r O M^{c}\left(X_{t}, Y_{t}\right) & =\mu_{X} X_{t} O M_{X}^{c}\left(X_{t}, Y_{t}\right)+\mu_{Y} Y_{t} O M_{Y}^{c}\left(X_{t}, Y_{t}\right) \\
& +\frac{1}{2} \sigma_{X}^{2} X_{t}^{2} O M_{X X}^{c}\left(X_{t}, Y_{t}\right)+\frac{1}{2} \sigma_{Y}^{2} Y_{t}^{2} O M_{Y Y}^{c}\left(X_{t}, Y_{t}\right)+\rho \sigma_{X} \sigma_{Y} X_{t} Y_{t} O M_{X Y}^{c}\left(X_{t}, Y_{t}\right)
\end{aligned}
$$

Because $O M^{c}\left(X_{t}, Y_{t}\right)$ is linearly homogeneous in $X_{t}$ and $Y_{t}$. We set the ratio of per unit capital of the acquirer and target as

$$
R_{t}=\frac{X_{t}}{Y_{t}}
$$

Therefore we rewrite the option function as

$$
O M^{c}\left(X_{t}, Y_{t}\right)=\max _{\tau^{c}} \mathbb{E}\left\{\mathrm{e}^{-r \tau} Y_{\tau^{c}}\left[p K_{B} R_{\tau^{c}}-K_{T}\right]\right\} .
$$

According to (A.3), the payoff function increases with the ration $R_{t}$. When the ratio reaches a certain threshold $R^{c}$, target firm will obtain the offer and sell their shares. Accordingly, we assume,

$$
O M^{c}\left(X_{t}, Y_{t}\right)=Y_{t} g^{c}\left(R_{t}\right)
$$


The successive differentiation equations of $O M(X, Y)$ give

$$
\begin{aligned}
& O M^{c}\left(X_{t}, Y_{t}\right)=g_{R}^{c}\left(R_{t}\right), \\
& O M_{Y}^{c}\left(X_{t}, Y_{t}\right)=g^{c}\left(R_{t}\right)-R_{t} g_{R}^{c}\left(R_{t}\right), \\
& O M_{X X}^{c}\left(X_{t}, Y_{t}\right)=g_{R R}^{c}\left(R_{t}\right) / Y, \\
& O M_{Y Y}^{c}\left(X_{t}, Y_{t}\right)=R_{t}^{2} g_{R R}^{c}\left(R_{t}\right) / Y, \\
& O M_{X Y}^{c}\left(X_{t}, Y_{t}\right)=-R_{t} g_{R R}^{c}\left(R_{t}\right) / Y .
\end{aligned}
$$

Substituting the successive differentiation equations above into the partial differential equation (A.3) yields the ordinary differential equation,

$$
\left(\frac{1}{2} \sigma_{X}^{2}+\frac{1}{2} \sigma_{Y}^{2}-\rho \sigma_{X} \sigma_{Y}\right) R^{2} g_{R R}^{c}\left(R_{t}\right)+\left(\mu_{X}-\mu_{Y}\right) R g_{R}^{c}\left(R_{t}\right)-\left(r-\mu_{Y}\right) g^{c}\left(R_{t}\right)=0 .
$$

Suppose a general solution $g^{c}\left(R_{t}\right)=A R_{t}^{\vartheta_{1}}+C R_{t}^{\vartheta_{2}}$, where $\vartheta_{1}>1$ and $\vartheta_{2}<0$ are roots of the quadratic equation of (9). As the no-bubble condition $\lim _{R_{t} \rightarrow 0} g_{t}^{c}=0$, the solution of (A.10) is

$$
g^{c}\left(R_{t}\right)=A R_{t}^{\vartheta_{1}}, \quad \vartheta_{1}>1 .
$$

(A.11) can be solved subjecting to the value-matching and smoothing-pasting conditions as

$$
\begin{aligned}
& A R_{\tau^{c}}^{\vartheta_{1}}=p K_{B} R_{\tau^{c}}-K_{T}, \\
& \vartheta_{1} A R_{\tau^{c}}^{\vartheta_{1}-1}=p K_{B} .
\end{aligned}
$$

Solving the equations above yields the results

$$
\begin{aligned}
& R_{\tau^{c}}=\frac{\vartheta_{1}}{\vartheta_{1}-1} \frac{K_{T}}{K_{B}} \frac{1}{p}, \\
& A=\left(p K_{B} R_{\tau^{c}}-K_{T}\right)\left(R_{\tau^{c}}\right)^{-\vartheta_{1}} .
\end{aligned}
$$

\section{B Proof of Lemma 2}

Submitting the results of Lemma 1 into the optimization function (10) is given by

$$
O T^{c}\left(X_{t}, Y_{t}\right)=\max _{p}\left\{Y_{t}\left[K_{T}\left(\alpha R_{\tau^{c}}-\alpha-c+1\right)-p K_{B} R_{\tau^{c}}\right]\left(\frac{R_{t}}{\left.R_{\tau^{c}}\right)}\right)^{\vartheta_{1}}\right\}
$$

Suppose

$$
O T^{c}\left(X_{t}, Y_{t}\right)=Y_{t} g^{o t c}\left(R_{t}\right)
$$

where

$$
g^{\text {otc }}\left(R_{t}\right)=\max _{p}\left\{\left[K_{T}\left(\alpha R_{\tau^{c}}-\alpha-c+1\right)-p K_{B} R_{\tau^{c}}\right]\left(\frac{R_{t}}{R_{\tau^{c}}}\right)^{\vartheta_{1}}\right\} .
$$

Maximizing function (B.3) yields,

$$
p=\frac{\alpha\left(\vartheta_{1}-1\right)}{(\alpha+c-1)\left(\vartheta_{1}-1\right)+\vartheta_{1}} \frac{K_{T}}{K_{B}} .
$$




\section{Proof of Lemma 3}

Substituting the firm's post-merger value given by (3) into the value of the option for the target, given by (13), yields

$$
O M\left(X_{t}, Y_{t}\right)=\max _{\tau} \mathbb{E}\left\{\mathrm{e}^{-r \tau}\left[(1-\xi)\left(S_{B}\left(X_{\tau}\right)+S_{T}\left(Y_{\tau}\right)+G_{M}\left(X_{\tau}, Y_{\tau}\right)\right)-(1-\lambda) K_{T} Y_{\tau}\right]\right\},
$$

which is in the region for the two state variables. According to Itô's lemma, the payoff function (C.1) satisfies the partial differential equation

$$
\begin{aligned}
r O M\left(X_{t}, Y_{t}\right)= & \mu_{X} X_{t} O M_{X}\left(X_{t}, Y_{t}\right)+\mu_{Y} Y_{t} O M_{Y}\left(X_{t}, Y_{t}\right) \\
& +\frac{1}{2} \sigma_{X}^{2} X_{t}^{2} O M_{X X}\left(X_{t}, Y_{t}\right)+\frac{1}{2} \sigma_{Y}^{2} Y_{t}^{2} O M_{Y Y}\left(X_{t}, Y_{t}\right)+\rho \sigma_{X} \sigma_{Y} X_{t} Y_{t} O M_{X Y}\left(X_{t}, Y_{t}\right) .
\end{aligned}
$$

The synergy $G_{M}\left(X_{t}, Y_{t}\right)$ is linearly homogeneous in $X_{t}$ and $Y_{t}$ according to assumption (4). We can rewrite the synergy (4) as

$$
G_{M}\left(X_{t}, Y_{t}\right)=Y_{t} g_{R}^{G}\left(R_{t}\right)
$$

where

$$
g_{R}^{G}\left(R_{t}\right)=K_{T}\left[\alpha\left(R_{t}-1\right)-c\right]
$$

Substituting (C.3) and (C.4) into (C.1) yields the payoff function

$$
O M\left(X_{t}, Y_{t}\right)=\max _{\tau} \mathbb{E}\left\{\mathrm{e}^{-r \tau} Y_{\tau}\left[(1-\xi)\left(K_{B}+\alpha K_{T}\right) R_{\tau}+[(1-\xi)(1-\alpha-c)-(1-\lambda)] K_{T}\right]\right\} .
$$

The payoff function above increases with the ratio $R_{t}$. We can assume that when the ratio reaches a certain threshold $R^{m}$, the target firm will accept the offer and merge with the acquirer. Suppose

$$
O M\left(X_{t}, Y_{t}\right)=Y_{t} g^{o m}\left(R_{t}\right)
$$

Successive differentiation equations of (C.6) with respect to $R_{t}$ give

$$
\begin{aligned}
& O M_{X}\left(X_{t}, Y_{t}\right)=g_{R}^{o m}\left(R_{t}\right) \\
& O M_{Y}\left(X_{t}, Y_{t}\right)=g^{o m}\left(R_{t}\right)-R_{t} g_{R}^{\text {sale }}\left(R_{t}\right) \\
& O M_{X X}\left(X_{t}, Y_{t}\right)=g_{R R}^{o m}\left(R_{t}\right) / Y_{t} \\
& O M_{Y Y}\left(X_{t}, Y_{t}\right)=R_{t}^{2} g_{R R}^{o m}\left(R_{t}\right) / Y_{t} \\
& O M_{X Y}\left(X_{t}, Y_{t}\right)=-R_{t} g_{R R}^{o m}\left(R_{t}\right) / Y_{t}
\end{aligned}
$$

Substituting equations (C.7)-(C.11) into (C.2) yields the ordinary differential equation

$$
\left(\frac{1}{2} \sigma_{X}^{2}+\frac{1}{2} \sigma_{Y}^{2}-\rho \sigma_{X} \sigma_{Y}\right) R^{2} g_{R R}^{o m}\left(R_{t}\right)+\left(\mu_{X}-\mu_{Y}\right) R g_{R}^{o m}\left(R_{t}\right)-\left(r-\mu_{Y}\right) g^{o m}\left(R_{t}\right)=0 .
$$

Suppose the general solution of (C.12) is $g^{o m}\left(R_{t}\right)=D R_{t}^{\vartheta_{1}}+E R_{t}^{\vartheta_{2}}$, where $\vartheta_{1}>1$ and $\vartheta_{2}<0$ are roots of the quadratic equation of (9). As the no-bubble condition $\lim _{R_{t} \rightarrow 0} g^{\text {sale }}\left(R_{t}\right)=0$, we have the solution

$$
g^{o m}\left(R_{t}\right)=D R_{t}^{\vartheta_{1}}, \quad \vartheta_{1}>1
$$


We can solve $g^{o m}\left(R_{t}\right)$ subject to the value-matching and smoothing-pasting conditions

$$
\begin{aligned}
& \left.g^{o m}\left(R_{t}\right)\right|_{t=\tau^{m}}=\left.g^{G}\left(R_{t}\right)\right|_{t=\tau^{m}}, \\
& \left.g_{R}^{o m}\left(R_{t}\right)\right|_{t=\tau^{m}}=\left.g_{R}^{G}\left(R_{t}\right)\right|_{t=\tau^{m}} .
\end{aligned}
$$

The target will accept the offer at $\tau^{m}$ and $R_{t}=R^{m}$ at $\tau^{m}$. Substituting equations (C.5) and (C.13) into (C.14) $-($ C.15) yields

$$
\begin{aligned}
& D\left(R^{m}\right)^{\vartheta_{1}}=(1-\xi)\left(K_{B}+\alpha K_{T}\right) R^{m}+[(1-\xi)(1-\alpha-c)-(1-\lambda)] K_{T}, \\
& \vartheta_{1} D\left(R^{m}\right)^{\vartheta_{1}-1}=(1-\xi)\left(K_{B}+\alpha K_{T}\right) .
\end{aligned}
$$

Solving the equations above yields

$$
\begin{aligned}
R^{m}(\lambda) & =\left[(\alpha+c-1)+\frac{1-\lambda}{1-\xi}\right] \frac{\vartheta_{1}}{\vartheta_{1}-1} \frac{K_{T}}{K_{B}+\alpha K_{T}}, \\
D & =\frac{(1-\xi)(\alpha+c-1)+(1-\lambda)}{\vartheta_{1}-1} K_{T}\left(R^{m}(\lambda)\right)^{-\vartheta_{1}} .
\end{aligned}
$$

Because $R^{m}(\lambda)$ is positive, the following inequality is satisfied,

$$
\lambda<(\alpha+c)(1-\xi)+\xi
$$

Substituting the results above into (C.13) yields

$$
g^{o m}\left(R_{t}\right)=\frac{(1-\xi)(\alpha+c-1)+(1-\lambda)}{\vartheta_{1}-1} K_{T}\left(\frac{R_{t}}{R^{m}(\lambda)}\right)^{\vartheta_{1}}
$$

Therefore,

$$
O M\left(X_{t}, Y_{t}\right)=Y_{t}\left(\frac{(1-\xi)(\alpha+c-1)+(1-\lambda)}{\vartheta_{1}-1} K_{T}\right)\left(\frac{R_{t}}{R^{m}(\lambda)}\right)^{\vartheta_{1}}
$$

where $R_{t}=X_{t} / Y_{t}$.

\section{Proof of Proposition 1}

Submitting the result of Lemma 3 into the optimization function (17), we have

$$
O T\left(X_{t}, Y_{t}\right)=\max _{\lambda^{m}} Y_{t}\left\{\left[\left((\xi-1) K_{B}+\xi \alpha K_{T}\right) R^{m}\left(\lambda^{m}\right)+\left(\xi(1-\alpha-c)-\lambda^{m}\right) K_{T}\right]\left(\frac{R_{t}}{R^{m}\left(\lambda^{m}\right)}\right)^{\vartheta_{1}}\right\} .
$$

The value function (D.1) is linearly homogeneous in $X_{t}$ and $Y_{t}$; thus, we assume

$$
O T\left(X_{t}, Y_{t}\right)=Y_{t} g^{o t}\left(R_{t}\right)
$$

where

$$
g^{o t}\left(R_{t}\right)=\max _{\lambda^{m}}\left\{\left[\left((\xi-1) K_{B}+\xi \alpha K_{T}\right) R^{m}\left(\lambda^{m}\right)+\left(\xi(1-\alpha-c)-\lambda^{m}\right) K_{T}\right]\left(\frac{R_{t}}{R^{m}\left(\lambda^{m}\right)}\right)^{\vartheta_{1}}\right\} .
$$


We can solve the optimization problem when

$$
\frac{d g^{o t}\left(R_{t}\right)}{d \lambda^{m}}=0
$$

The result of condition (D.4) is

$$
\lambda^{m}=(\alpha+c)(1-\xi)+\xi+\frac{\vartheta_{1}(\alpha+c)(1-\xi)\left(K_{B}+\alpha K_{T}\right)}{(1-\xi) K_{B}-\alpha\left(\vartheta_{1}+\xi-1\right) K_{T}} .
$$

Therefore,

$$
R^{m}=\frac{\vartheta_{1}^{2}}{\vartheta_{1}-1} \frac{(\alpha+c) K_{T}}{\alpha\left(\vartheta_{1}+\xi-1\right) K_{T}-(1-\xi) K_{B}} .
$$

\section{E Proof of Proposition 2}

We can solve the maximization problem (20) when the terms satisfies

$$
\beta \frac{d O T\left(X_{t}, Y_{t} ; \xi\right)}{d \xi}+(1-\beta) \frac{O T\left(X_{t}, Y_{t} ; \xi\right)}{O M\left(X_{t}, Y_{t} ; \xi\right)} \frac{d O M\left(X_{t}, Y_{t} ; \xi\right)}{d \xi}=0
$$

According to equations (C.6) and (D.2), we can rewrite (E.1) as

$$
\beta \frac{d g^{o t}\left(R_{t} ; \xi\right)}{d \xi}+(1-\beta) \frac{g^{o t}\left(R_{t} ; \xi\right)}{g^{o m}\left(R_{t} ; \xi\right)} \frac{d g^{o m}\left(R_{t} ; \xi\right)}{d \xi}=0 .
$$

Substituting the optimal acquisition premium $\lambda^{m}$, given by (18), and the threshold (19) into the payoff function (D.3), yields

$$
g^{o t}\left(R_{t} ; \xi\right)=\frac{(\alpha+c) K_{T}}{\vartheta_{1}-1}\left(\frac{R_{t}}{R^{m}\left(\lambda^{m} ; \xi\right)}\right)^{\vartheta_{1}}
$$

The first-order derivative of (E.3) with respect to $\xi$ is

$$
\frac{d g^{o t}\left(R_{t} ; \xi\right)}{d \xi}=\frac{\vartheta_{1}}{\vartheta_{1}-1} \frac{(\alpha+c) K_{T}\left(\alpha K_{T}+K_{B}\right)}{\alpha\left(\vartheta_{1}+\xi-1\right) K_{T}-(1-\xi) K_{B}}\left(\frac{R_{t}}{R^{m}\left(\lambda^{m} ; \xi\right)}\right)^{\vartheta_{1}}
$$

Substituting (18) into (C.20) yields

$$
g^{o m}\left(R_{t} ; \xi\right)=\frac{\vartheta_{1}}{\vartheta_{1}-1} \frac{(1-\xi)(\alpha+c)\left(K_{B}+\alpha K_{T}\right) K_{T}}{\alpha \vartheta_{T}-(1-\xi)\left(K_{B}+\alpha K_{T}\right)}\left(\frac{R_{t}}{R^{m}\left(\lambda^{m} ; \xi\right)}\right)^{\vartheta_{1}}
$$

The first-order derivative of (E.5) with respect to $\xi$ is

$$
\frac{d g^{o m}\left(R_{t} ; \xi\right)}{d \xi}=\frac{\vartheta_{1}^{2}}{\vartheta_{1}-1} \frac{(\alpha+c)\left((1-\xi)\left(K_{B}+\alpha K_{T}\right)-\alpha K_{T}\right)\left(K_{B}+\alpha K_{T}\right) K_{T}}{\left[\alpha \vartheta_{1} K_{T}-(1-\xi)\left(K_{B}+\alpha K_{T}\right)\right]^{2}}\left(\frac{R_{t}}{R^{m}\left(\lambda^{m} ; \xi\right)}\right)^{\vartheta_{1}}
$$

Substituting equations (E.3)-(E.6) into (E.2) gives

$$
1-\xi=\frac{(1-\beta) \alpha K_{T}}{K_{B}+\alpha K_{T}}
$$




\section{F Proof of Lemma 4}

We can simplify the target firm's value of the option, given by (28), as

$$
O M^{i m}\left(X_{t}, Y_{t}\right)=\max _{\tau^{i m}} \mathbb{E}\left\{\mathrm{e}^{-r \tau^{i m}}\left[(1-\xi)\left(K_{B}+\alpha K_{T}\right) X_{\tau^{i m}}+\left((1-\xi)\left(1-\alpha \omega_{T}-c\right)-(1-\lambda)\right) K_{T} Y_{\tau^{i m}}\right]\right\} .
$$

Assume $O M^{i m}\left(X_{t}, Y_{t}\right)=Y_{t} \tilde{g}^{o m}\left(R_{t}\right)$, which satisfies the ordinary differential equation

$$
\left(\frac{1}{2} \sigma_{X}^{2}+\frac{1}{2} \sigma_{Y}^{2}-\rho \sigma_{X} \sigma_{Y}\right) R_{t}^{2} \tilde{g}_{R R}^{o m}\left(R_{t}\right)+\left(\mu_{X}-\mu_{Y}\right) R_{t} \tilde{g}_{R}^{o m}\left(R_{t}\right)-\left(r-\mu_{Y}\right) \tilde{g}^{o m}\left(R_{t}\right)=0 .
$$

Suppose $\tilde{g}^{o m}\left(R_{t}\right)=F R_{t}^{\vartheta_{1}}$, where $\vartheta_{1}$ is the positive root of $(9)$. We can solve $\tilde{g}^{o m}\left(R_{t}\right)$ subject to the value-matching and smoothing-pasting conditions below

$$
\begin{aligned}
& F\left(R^{i m}\right)^{\vartheta_{1}}=(1-\xi)\left(K_{B}+\alpha K_{T}\right) R^{i m}+\left((1-\xi)\left(1-\alpha \omega_{T}-c\right)-(1-\lambda)\right) K_{T}, \\
& \vartheta_{1} F\left(R^{i m}\right)^{\vartheta_{1}-1}=(1-\xi)\left(K_{B}+\alpha K_{T}\right) .
\end{aligned}
$$

Solving the equations above yields,

$$
\begin{aligned}
& R^{i m}(\lambda, \xi)=\left(\alpha \omega_{T}+c-1+\frac{1-\lambda}{1-\xi}\right) \frac{\vartheta_{1}}{\vartheta_{1}-1} \frac{K_{T}}{K_{B}+\alpha K_{T}}, \\
& F=\frac{(1-\xi)\left(\alpha \omega_{T}+c-1\right)+(1-\lambda)}{\vartheta_{1}-1} K_{T}\left(R^{m}(\lambda, \xi)\right)^{-\vartheta_{1}} .
\end{aligned}
$$

where $R^{i m}(\lambda, \xi)$ is positive, the following inequality is satisfied,

$$
\lambda<\xi+\left(\alpha \omega_{T}+c\right)(1-\xi)
$$

And,

$$
\tilde{g}^{o m}\left(R_{t}\right)=\frac{(1-\xi)\left(\alpha \omega_{T}+c-1\right)+(1-\lambda)}{\vartheta_{1}-1} K_{T}\left(\frac{R_{t}}{R^{i m}(\lambda, \xi)}\right)^{\vartheta_{1}}
$$

where $R_{t}=X_{t} / Y_{t}$.

\section{G Proof of Proposition 3}

Substituting (1)-(4) into the optimization function (32) yields,

$$
\begin{aligned}
& O T^{i m}\left(X_{t}, Y_{t}\right)= \\
& \max _{\lambda^{i m}} Y_{t}\left\{\left[\left((\xi-1) K_{B}+\xi \alpha \omega_{B} K_{T}\right) R^{m}\left(\lambda^{i m}, \xi\right)+\left[\xi(1-\alpha-c)-\lambda^{i m}\right] K_{T}\right]\left(\frac{R_{t}}{R^{m}\left(\lambda^{i m}, \xi\right)}\right)^{\vartheta_{1}}\right\},
\end{aligned}
$$

where $R^{m}\left(\lambda^{i m}, \xi\right)$ is given by (14). And suppose

$$
O T^{i m}\left(X_{t}, Y_{t}\right)=Y_{t} \tilde{g}^{o t}\left(R_{t}\right) \text {, }
$$


where $\tilde{g}^{o t}\left(R_{t}\right)$ is given by

$$
\tilde{g}^{o t}\left(R_{t}\right)=\max _{\lambda^{i m}}\left\{\left[\left((\xi-1) K_{B}+\xi \alpha \omega_{B} K_{T}\right) R^{m}\left(\lambda^{i m}, \xi\right)+\left[\xi(1-\alpha-c)-\lambda^{i m}\right] K_{T}\right]\left(\frac{R_{t}}{R^{m}\left(\lambda^{i m}, \xi\right)}\right)^{\vartheta_{1}}\right\} .
$$

The optimization problem is maximized when

$$
\frac{d \tilde{g}^{o t}\left(R_{t}\right)}{d \lambda^{i m}}=0 .
$$

Therefore, the optimal offered portion satisfies

$$
\begin{aligned}
\left(\vartheta_{1}-1\right) & \left((\xi-1) K_{B}+\xi \alpha \omega_{B} K_{T}\right) \frac{d R^{m}\left(\lambda^{i m}, \xi\right)}{d \lambda^{i m}} \\
& +\vartheta_{1}\left(\xi(1-\alpha-c) K_{T}-\lambda^{i m} K_{T}\right) \frac{1}{R^{m}\left(\lambda^{i m}, \xi\right)} \frac{d R^{m}\left(\lambda^{i m}, \xi\right)}{d \lambda^{i m}}+K_{T}=0 .
\end{aligned}
$$

Solving the equation above yields

$$
\lambda^{i m}=(1-\xi)(\alpha+c)+\xi+\frac{\vartheta_{1}(\alpha+c)(1-\xi)\left(K_{B}+\alpha K_{T}\right)}{(1-\xi) K_{B}-\alpha\left(\left(\vartheta_{1}+\xi-1\right)+\vartheta_{1} \xi\left(\omega_{B}-1\right)\right) K_{T}} .
$$

Substituting the result above into (29) gives

$$
R^{i m}=\frac{\vartheta_{1}}{\vartheta_{1}-1}\left(\frac{\alpha\left(\omega_{T}-1\right) K_{T}}{K_{B}+\alpha K_{T}}+\frac{\vartheta_{1}(\alpha+c) K_{T}}{\alpha\left(\left(\vartheta_{1}+\xi-1\right)+\vartheta_{1} \xi\left(\omega_{B}-1\right)\right) K_{T}-(1-\xi) K_{B}}\right) .
$$

\section{H Proof of Proposition 4}

According to the optimization function (35), the optimal terms satisfies

$$
\beta \frac{d \tilde{g}^{o t}\left(R_{t} ; \xi^{i m}\right)}{d \xi^{i m}}+(1-\beta) \frac{\tilde{g}^{o t}\left(R_{t} ; \xi^{i m}\right)}{\tilde{g}^{o m}\left(R_{t} ; \xi^{i m}\right)} \frac{d \tilde{g}^{o m}\left(R_{t} ; \xi^{i m}\right)}{d \xi^{i m}}=0 .
$$

For the acquirer firm, $\omega_{T}$ keeps unknown until the merger succeeds. Therefore, they will provide an optimal acquisition premium $\lambda^{i m}$ which is given by (33) and estimate that the threshold which the target will accept the offer is (14) which is the threshold in a market with perfect information. Substituting (14) and (33) into (G.3) yields

$$
\begin{aligned}
\tilde{g}^{o t}\left(R_{t} ; \xi\right) & =\left\{\left(\xi\left(K_{B}+\alpha \omega_{B} K_{T}\right)-K_{B}\right) R^{m}\left(\lambda^{i m}, \xi\right)+\left(\xi(1-\alpha-c)-\lambda^{i m}\right) K_{T}\right\}\left(\frac{R_{t}}{R^{m}\left(\lambda^{i m}, \xi\right)}\right)^{\vartheta_{1}}, \\
& =\frac{(\alpha+c) K_{T}}{\vartheta_{1}-1}\left(\frac{R_{t}}{R^{m}\left(\lambda^{i m}, \xi\right)}\right)^{\vartheta_{1}} .
\end{aligned}
$$


According to the result of $(14), R^{m}\left(\lambda^{i m}, \xi\right)$ satisfies

$$
\frac{1}{R^{m}\left(\lambda^{i m}, \xi\right)} \frac{d R^{m}\left(\lambda^{i m}, \xi\right)}{d \xi}=\left(-\frac{d \lambda^{i m}}{d \xi}+\frac{1-\lambda^{i m}}{1-\xi}\right) \frac{1}{(1-\xi)(\alpha+c-1)+1-\lambda^{i m}} .
$$

The first-order derivative of (H.2) with respect to $\xi$ is

$$
\begin{aligned}
\frac{d \tilde{g}^{o t}\left(R_{t} ; \xi\right)}{d \xi} & =-(\alpha+c) K_{T} \frac{\vartheta_{1}}{\vartheta_{1}-1}\left(\frac{R_{t}}{R^{m}\left(\lambda^{i m}, \xi\right)}\right)^{\vartheta_{1}} \frac{1}{R^{m}\left(\lambda^{i m}, \xi\right)} \frac{d R^{m}\left(\lambda^{i m}, \xi\right)}{d \xi}, \\
& =\frac{\vartheta_{1}}{\vartheta_{1}-1}\left(\frac{R_{t}}{R^{m}\left(\lambda^{i m}, \xi\right)}\right)^{\vartheta_{1}}\left(\frac{d \lambda^{i m}}{d \xi}-\frac{1-\lambda^{i m}}{1-\xi}\right) \frac{(\alpha+c) K_{T}}{(1-\xi)(\alpha+c-1)+1-\lambda^{i m}} .
\end{aligned}
$$

Substituting (H.2)-(H.4) into the optimization function (H.1), we have

$$
\begin{aligned}
\frac{\alpha}{\alpha+c} \frac{K_{T}}{K_{B}+\alpha K_{T}} \frac{\omega_{B}}{1-\xi}\left((1-\xi)\left(\alpha \omega_{T}+c-1\right)+\left(1-\lambda^{i m}\right)\right)^{2} & (1-\beta) \\
=(1-\xi)(\alpha+c-1)+\left(1-\lambda^{i m}\right) & \\
& +\frac{\beta \vartheta_{1}}{(1-\xi)(\alpha+c-1)+\left(1-\lambda^{i m}\right)}-\frac{(1-\beta)\left(1-\vartheta_{1}\right)}{(1-\xi)\left(\alpha \omega_{T}+c-1\right)+\left(1-\lambda^{i m}\right)}
\end{aligned}
$$

To simplify the equation, we set

$$
\begin{aligned}
& \gamma_{1}=(1-\xi)(\alpha+c-1)+\left(1-\lambda^{i m}\right), \\
& \gamma_{2}=(1-\xi)\left(\alpha \omega_{T}+c-1\right)+\left(1-\lambda^{i m}\right) .
\end{aligned}
$$

Therefore, the optimal terms satisfies

$$
\frac{\alpha}{\alpha+c} \frac{K_{T}}{K_{B}+\alpha K_{T}} \frac{\omega_{B}}{1-\xi}=\frac{\gamma_{1}}{\gamma_{2}^{2}}+\frac{(1-\beta) \gamma_{1}}{\beta \vartheta_{1} \gamma_{2}^{2}-(1-\beta)\left(1-\vartheta_{1}\right) \gamma_{1} \gamma_{2}} .
$$

\section{Acknowledgment}

The author would like to thank Professor Makoto Goto, the editor Motoh Tsujimura and two anonymous referees for their valuable comments.

\section{References}

[1] Azevedo A. and Paxson D. (2014): Developing real option game models, European Journal of Operational Research, 237, 909-920.

[2] Bernile, G., Lyandres, E. and Zhdanov, A. (2012): A theory of strategic mergers, Review of Finance, 16, 517-575.

[3] Banerjee, S., Güçbilmez, U. and Pawlina, G. (2014): Optimal exercise of jointly held real options: A Nash bargaining approach with value diversion, European Journal of Operational Research, 239, $565-578$. 
[4] Faccio, M. and Masulis, R. W. (2005): The choice of payment method in European mergers and acquisitions, Journal of Finance, 60, 1345-1388.

[5] Gaughan, P. A. (2015): Mergers, Acquisitions, and Corporate Restructurings, 6th edition, John Wiley \& Sons.

[6] Goergen, M. and Renneboog, L. (2004): Shareholder wealth effects of European domestic and cross-border takeover bids, European Financial Management, 10, 9-45.

[7] Hackbarth, D. and Miao, J. (2012): The dynamics of mergers and acquisitions in oligopolistic industries, Journal of Economic Dynamics and Control, 36, 585-609.

[8] Hackbarth, D. and Morellec, E. (2008): Stock returns in mergers and acquisitions, Journal of Finance, 63, 1213-1252.

[9] de La Bruslerie, H. (2012): Corporate acquisition process: Is there an optimal cash-equity payment mix?, International Review of Law and Economics, 32, 83-94.

[10] Lambrecht, B. (2004): The Timing and Terms of Mergers Motivated by Economies of Scale, Journal of Financial Economics, 72, 41-62.

[11] Lambrecht, B. and Myers, S. (2007): A Theory of Takeovers and Disinvestment, Journal of Finance, 62, 809-845.

[12] Lukas, E. and Welling, A. (2012): Negotiating M\&As under uncertainty: The influence of managerial flexibility on the first-mover advantage, Finance Research Letters, 9, 29-35.

[13] Lukas, E., Reuer, J. and Welling, A. (2012): Earnouts in mergers and acquisitions: A gametheoretic option pricing approach, European Journal of Operational Research, 223, 256-263.

[14] Martynova, M. and Renneboog, L. (2009): What determines the financing decision in corporate takeovers: Cost of capital, agency problems, or the means of payment?, Journal of Corporate Finance, 15, 290-315.

[15] Moeller, S., Schlingemann, F. and Stulz, R. (2004): Firm size and the gains from acquisitions, Journal of Financial Economics, 73, 201-228.

[16] Morellec, E. and Zhdanov, A. (2005): The dynamics of mergers and acquisitions, Journal of Financial Economics, 77, 649-672.

[17] Nash, J. F. (1950): The Bargaining Problem, Econometrica, 18, 155-162.

[18] Offenberg, D. and Pirinsky, C. (2015): How do acquirers choose between mergers and tender offers?, Journal of Financial Economics, 116, 331-348.

[19] Shleifer, A. and Vishny, R. (2003): Stock market driven acquisitions, Journal of Financial Economics, 70, 295-311.

[20] Raua, P. R. and Vermaelen, T. (1998): Glamour, Value, and the post-Acquisition performance of acquiring Firms, Journal of Financial Economics, 49, 223-253. 
Mergers and Acquisitions Strategy under Imperfect Information: A Mixed-payment Model

[21] Thijssen, J. J. J (2008): Optimal and strategic timing of mergers and acquisitions motivated by synergies and risk diversification, Journal of Economic Dynamics and Control, 32, 1701-1720. 